\title{
ARTICLE
}

Check for

updates

Cite as

Nano-Micro Lett.

(2021) 13:59

Received: 8 November 2020

Accepted: 20 December 2020

Published online: 21 January 2021

(C) The Author(s) 2021

\section{Identifying Heteroatomic and Defective Sites in Carbon with Dual-Ion Adsorption Capability for High Energy and Power Zinc Ion Capacitor}

\author{
Wenjie Fan ${ }^{1,2}$, Jia Ding ${ }^{1}$, Jingnan Ding ${ }^{1}$, Yulong Zheng ${ }^{2}$, Wanqing Song ${ }^{1}$, \\ Jiangfeng Lin $^{1}$, Caixia Xiao ${ }^{1}$, Cheng Zhong ${ }^{1 凶}$, Huanlei Wang ${ }^{2}{ }^{凶}$, Wenbin $\mathrm{Hu}^{1} \bowtie$
}

\section{HIGHLIGHTS}

- A unique dual-ion adsorption mechanism for zinc ion capacitor is enabled by a carbon cathode with defect-rich tissue, dense heteroatom dopant and immense surface area.

- The active sites on carbon surface for reversible dual-ion adsorption are identified by in-depth characterizations and DFT simulations.

- The zinc ion capacitor delivers unrivaled combination of high energy and power characteristics. The superb energy, power and cyclability are achieved in multiple cell configurations including coin cell and flexible solid-state pouch-/cable-type cells.

ABSTRACT Aqueous zinc-based batteries (AZBs) attract tremen-
dous attention due to the abundant and rechargeable zinc anode.
Nonetheless, the requirement of high energy and power densities
raises great challenge for the cathode development. Herein we con-
struct an aqueous zinc ion capacitor possessing an unrivaled com-
bination of high energy and power characteristics by employing a
unique dual-ion adsorption mechanism in the cathode side. Through
a templating/activating co-assisted carbonization procedure, a rou-
tine protein-rich biomass transforms into defect-rich carbon with

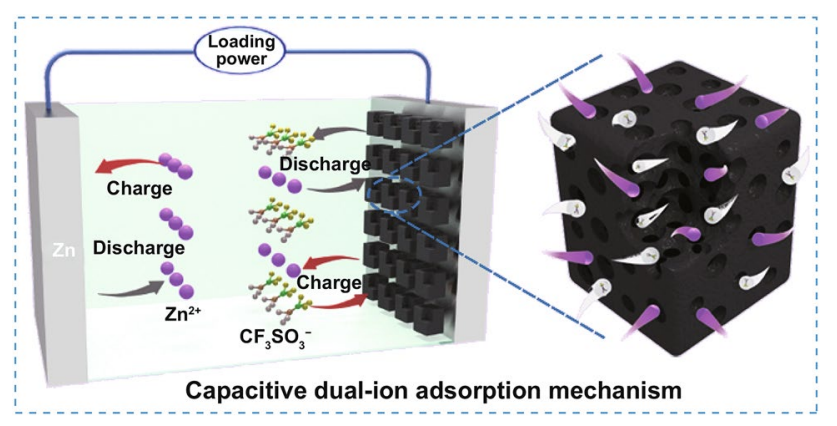
immense surface area of $3657.5 \mathrm{~m}^{2} \mathrm{~g}^{-1}$ and electrochemically active heteroatom content of 8.0 at\%. Comprehensive characterization and DFT calculations reveal that the obtained carbon cathode exhibits capacitive charge adsorptions toward both the cations and anions, which regularly occur at the specific sites of heteroatom moieties and lattice defects upon different depths of discharge/ charge. The dual-ion adsorption mechanism endows the assembled cells with maximum capacity of $257 \mathrm{mAh} \mathrm{g}^{-1}$ and retention of $72 \mathrm{mAh} \mathrm{g}^{-1}$ at ultrahigh current density of $100 \mathrm{~A} \mathrm{~g}^{-1}(400 \mathrm{C})$, corresponding to the outstanding energy and power of $168 \mathrm{Wh} \mathrm{kg}^{-1}$ and $61,700 \mathrm{~W} \mathrm{~kg}^{-1}$. Furthermore, practical battery configurations of solid-state pouch and cable-type cells display excellent reliability in electrochemistry as flexible and knittable power sources.

KEYWORDS Aqueous zinc ion capacitor; Dual-ion adsorption; Charge storage mechanism; High energy and power; Flexible and knittable devices

$\bigotimes$ Jia Ding, jiading@tju.edu.cn; Cheng Zhong, cheng.zhong@tju.edu.cn; Huanlei Wang, huanleiwang@ gmail.com; Wenbin Hu, wbhu@ @ju.edu.cn

1 Key Laboratory of Advanced Ceramics and Machining Technology (Ministry of Education), School of Materials Science and Engineering, Tianjin

University, Tianjin 300072, People's Republic of China

2 School of Materials Science and Engineering, Ocean University of China, Qingdao 266100, People's Republic of China 


\section{Introduction}

Owing to the high energy, high safety, low cost and potentiality of device flexibility, the aqueous zinc-based batteries (AZBs) become prospective candidates in the application scenarios of grid scale energy storage, electric vehicles and wearable flexible devices [1-4]. The advantages largely originate from the low redox potential, high gravimetric/ volumetric capacity and moderate chemical activity of the zinc metal anode, as well as the non-flammable, low-cost aqueous electrolyte [5-8]. Based on the universal zinc anode and aqueous electrolyte, the diversity of the cathodes creates various derivative battery systems, including aqueous zinc-air battery [9-11], zinc-nickel battery [12, 13], zinc-manganese battery [14-17], zinc-vanadium battery [18-21], etc. The most essential difference among these well-defined battery systems lies in the charge storage mechanisms in the cathode side, which can be categorized into electrocatalysis [22-25], conversion reactions [26], intercalation reactions [27, 28], phase transformations $[14,29]$, etc. Regardless of the multifarious charge storage mechanisms employed in the cathodes, the ultimate objective being pursued is to obtain combined characteristics of high energy and power densities for the AZBs, which yet remains a significant challenge.

By introducing the capacitive charge storage mechanism in the cathode side of AZBs, the coupling of cathode and zinc anode assembles into a hybrid zinc ion capacitor, which is considered as a promising configuration to make the high energy and high power compatible [30-32]. Theoretically, the zinc anode can deliver a battery-level energy associated with the zinc plating/striping processes, while the facile kinetics of the capacitive cathodes guarantees a supercapacitor-mode power, which creates the possibility of combining the advantages of two stand-along technologies [33-36]. The practical implement of this strategy raises high requirements for the capacitive cathode material. First, the specific capacity of the cathode material should be as high as possible to match the zinc anode counterpart $\left(820 \mathrm{mAh} \mathrm{g}^{-1}\right)$, thus minimizing the total active mass. Therefore, the routine HelmHoltz doublelayer capacitance is inadequate in this circumstance, but a synergy of various Faradic/non-Faradic charge storage mechanisms is highly desired. Second, the high power trait requires excellent capacity retention capability for the cathode at the extreme discharge/charge rates [37]; therefore, the sluggish kinetics of ion diffusion and charge transfer should be substantially eliminated.

Carbonaceous material is an important category of electrode material in various energy storage systems [38-42]. The wide applications are benefited from the high tenability in morphology, graphitic microstructure, porosity, surface chemistry, etc., for fulfilling different charge storage demands [43-46]. Carbon materials, for instance hollow carbon sphere [47], chemical activated graphene [30], heteroatoms doping porous carbon [48-50], etc., were attempted in hybrid zinc ion capacitors as the capacitive cathodes. These pioneering works are highly inspiring and reveal the great potential of applying carbons in advanced AZBs. Yet exploring carbons for high energy and power zinc ion capacitor is still in the infancy stage. According to our thorough literature survey, the current carbon cathodesbased zinc ion capacitors exhibited limited energy density of around $130 \mathrm{Wh} \mathrm{kg}^{-1}$. Also, the devices typically performed at moderate current densities of below $20 \mathrm{~A} \mathrm{~g}^{-1}$, leading to the power lower than $30 \mathrm{~kW} \mathrm{~kg}{ }^{-1}$. More importantly, as aforementioned, the energy/power behaviors of AZBs correlate closely with the charge storage mechanism in the cathode. By far there is a shortage of systematical study on the charge storage mechanism of carbon cathode in zinc ion capacitors, which significantly obstructs the material design and device performance promotion.

In this work, we utilized a common biomass of proteinrich bone glue for carbon preparation. Via a templating/ activating co-assisted carbonization procedure, the optimized carbon exhibits highly defect-rich graphitic tissue, $3657.5 \mathrm{~m}^{2} \mathrm{~g}^{-1}$ surface area, hierarchical porous structure and electrochemically active heteroatom doping of 8.0 at $\%$. The zinc ion capacitor employing BGC cathode delivered maximum energy and power densities of $168 \mathrm{Wh} \mathrm{kg}^{-1}$ and $61,700 \mathrm{~W} \mathrm{~kg}^{-1}$, respectively. Both experiments and density function theory calculation illustrate that the superior electrochemical performance is essentially attributed to the unique dual-ion adsorption mechanism. The massive heteroatom moieties and lattice defects distributing on carbon surface provide large population of sites for both $\mathrm{Zn}^{2+}$ and $\mathrm{CF}_{3} \mathrm{SO}_{3}{ }^{-}$adsorption, which exhibit capacitive kinetics in nature. 


\section{Experimental Section}

\subsection{Materials Synthesis}

The bone glue biomass was purchased from Hunan Jusuo Biotechnology Co., Ltd. Sodium phytate and sodium hydroxide were received from Shanghai aladdin Biochemical Technology Co., Ltd. and Sinopharm Chemical Reagent Co., Ltd. The bone glue-derived carbons (BGCs) were prepared using bone glue as biomass precursor, sodium phytate as salt template and sodium hydroxide as activating agent. In a typical synthesis process, two solutions were firstly prepared by dissolving $2 \mathrm{~g}$ bone glue and $0.5 \mathrm{~g}$ sodium phytate in 20 and $5 \mathrm{~mL}$ deionized water at $60{ }^{\circ} \mathrm{C}$, respectively. The solutions were mixed together and stirred at $60{ }^{\circ} \mathrm{C}$ for $4 \mathrm{~h}$, and the obtained composite was loaded in an oven at $100{ }^{\circ} \mathrm{C}$ for $6 \mathrm{~h}$ to evaporate the residual water. The dried mixture was calcined at $450{ }^{\circ} \mathrm{C}$ for $1 \mathrm{~h}$ under argon atmosphere. The heating rate is $5^{\circ} \mathrm{C} \mathrm{min}^{-1}$. After grinding the pre-carbonized products with sodium hydroxide in a mortar in a mass ratio of 1: 2, carbonization of the mixture was processed under $650 / 750 / 850{ }^{\circ} \mathrm{C}$ for $2 \mathrm{~h}$ with a heating rate of $5{ }^{\circ} \mathrm{C} \min ^{-1}$ in argon. The obtained products were washed by $\mathrm{HCl}$ and deionized water for several times and dried at $80^{\circ} \mathrm{C}$ for $12 \mathrm{~h}$. The as-prepared bone glue-derived carbon was named as BGC-T, where $\mathrm{T}$ is the temperature in the second carbonization step. A commercial activated carbon (named AC) was utilized as received.

\subsection{Materials Characterization}

To observe the morphology and microstructure of the carbons, a scanning electron microscope (SEM, Hitachi, S4800, $5 \mathrm{kV}$, Japan) and a transmission electron microscopy (TEM, JEOL, JSM-2100F, 200 kV, Japan) were employed. The X-ray diffraction (XRD) spectra were collected by Bruker D8 Advanced X-ray diffractometer (Bruker Corp., Billerica, MA, USA) with $\mathrm{Cu} \mathrm{K} \alpha$ radiation. The gas absorption-desorption isotherm was characterized via autosorb iQ instrument (Quantachrome, US) at $77 \mathrm{~K}$ with nitrogen as adsorbate. The specific surface area of the carbons was estimated by Brunauer-Emmett-Teller (BET) method. The pore volume and pore size distribution were determined on the basis of density functional theory (DFT) model. Raman spectra were obtained using a Raman spectrometer (Lab
RAM HR800, laser wavelength: $532 \mathrm{~nm}$, laser power: 5 $\mathrm{mW}$ ). X-ray photoelectron spectrometer (Axis Supra X, Japan) with $\mathrm{Al} \mathrm{K} \alpha$ radiation (1486.6 eV) was used to collect X-ray photoelectron spectroscopy (XPS). For XPS ex situ electrodes preparation, sodium carboxymethyl cellulose (CMC) and alcohol solution were utilized as binder and solvent. After charging/discharging to the target voltage, the cell disassembly was completed within $30 \mathrm{~s}$. The collected active materials were washed repeatedly with deionized water and vacuum-dried before XPS tests.

\subsection{DFT Calculation}

The involved calculations were proceeded via the Vienna Ab initio Software Package (VASP 5.3.5) code based on the density functional theory (DFT), in which the Perdew-Burke-Ernzerhof (PBE) generalized gradient approximation and projected augmented wave (PAW) method were employed [51-53]. The plane wave cutoff energy was set to $400 \mathrm{eV}$ in the all calculations. The Brillouin zone of the unit cell was sampled by Monkhorst-Pack (MP) method with Gamma centered in the $3 \times 3 \times 1$ Monkhorst-Pack grid [54]. A k-point mesh was used for graphene structure optimizations, in which the convergence criterion for the electronic self-consistent iteration and force was set to $10^{-5} \mathrm{eV}$ and $0.01 \mathrm{eV}^{-1}$, respectively [55]. In this study, we constructed a $5 \times 5$ graphene surface supercell, including an atomic layer, to simulate the graphitic lattice. A vacuum layer of $12 \AA$ was constructed to prevent the interaction between periodic layers. The ion adsorption energy $\left(E_{\text {ads }}\right)$ at various surface sites was estimated as follows:

$E_{\text {ads }}=E_{\text {total }}-E_{\text {surface }}-E_{\text {species }}$

in which the $E_{\text {total }}, E_{\text {surface }}$ and $E_{\text {species }}$ are representative of the total energy of the adsorbed species with graphene surface, the energy of the empty graphene surface and the energy of the specific adsorbed species in the gas phase, respectively.

\section{Results and Discussion}

\subsection{Morphology and Physicochemical Characterization}

Scheme 1 demonstrates the transformation of the bone glue precursor into the carbonaceous materials (BGCs). Bone 


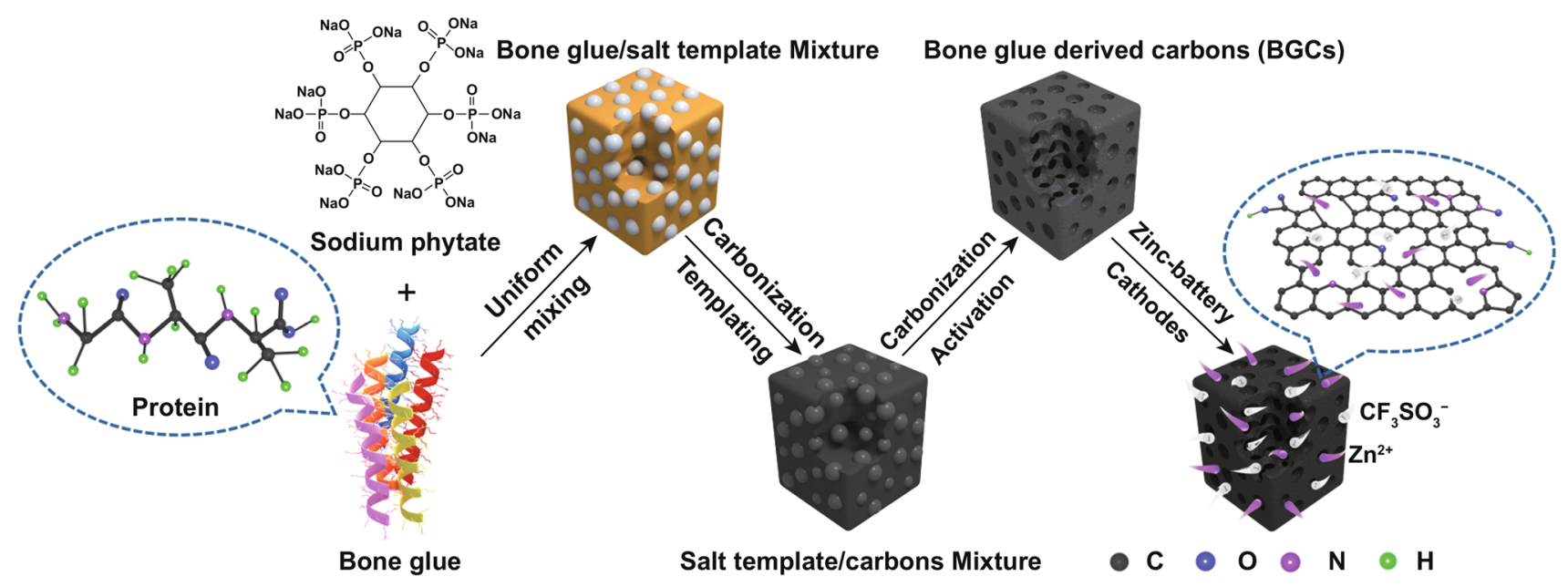

Scheme 1 A schematic illustrating the preparation procedure of the bone glue-derived carbons (BGCs)

glue is a daily protein biomass mainly composed of polypeptide chains. The abundant elements of nitrogen and oxygen in the polypeptide can create intrinsic heteroatom doping for the obtained carbons. The preparation route involves twostep carbonization with the co-assistance of template and activation agents. It is of great importance that the bone glue melts above the temperature of $60{ }^{\circ} \mathrm{C}$, when the gelatinous precursor can easily achieve uniform blend with the salt template of sodium phytate. The sodium phytate template not only generates macro-/meso-porosity after scarifying but also aids the sodium hydroxide to maximize the activation effect. According to the controlling experiments, the temperature in this templating/activating co-assistant carbonization procedure plays a vital role in tuning the physicochemical properties of the obtained carbon, as will be further discussed.

Figure 1a shows the scanning electron microscopy (SEM) image of the optimized BGC sample with carbonization temperature of $750{ }^{\circ} \mathrm{C}$ (BGC-750), highlighting the honeycomblike macroporous morphology. The SEM image with higher magnification (Fig. S1a) reveals the abundant $0.3-1 \mu \mathrm{m}$ voids in the carbon bulk, which is largely attributed to the synergy of salt template removal and intense activating etch $[43,56]$. As comparison, the BGC-650 shows visibly fewer macrovoids or cavities since the low temperature has much weaker activation effect (Fig. S1b). On the contrary, $850^{\circ} \mathrm{C}$ is too high for activation; thus, the carbon framework collapsed and isolate macropores were largely destroyed [57], as evidenced by the mostly closed morphology of BGC-850 (Fig. S1c). The commercial activated carbon (AC) baseline exhibits solid micron-size particle morphology without any observable open macroporosity (Fig. S1d). Figure 1b demonstrates the transition electron microscopy (TEM) image of BGC-750. The interconnected macroporosity below $500 \mathrm{~nm}$ in the carbon bulk can be better observed. The high-resolution TEM image in Fig. 1c displays a highly disordered graphitic microstructure of BGC-750. Negligible continuous graphene fringe appears. Instead, massive micropores and defects clearly present on the surface.

The graphitic structure of BGCs and AC was first studied by XRD. Figure $1 \mathrm{~d}$ exhibits the resulted spectra. The BGCs and AC all demonstrate broad (002) and (100) humps that are resulted from the amorphous carbonaceous tissue. In order to distinguish the delicate difference in graphitic microstructure among the samples, we utilized an empirical parameter $R$ as an indicator of the number of carbon sheets arranged as single layers [58]. The method for $R$ calculation and the corresponding values are shown in Fig. S2 and Table $\mathrm{S} 1$. Basically a lower $R$ value is reflective of more randomly stacked graphene layers without ordered orientations, which closely correlates with the degree of disorder. Referring to Fig. 1f, the $R$ values of BGCs almost linearly increase upon higher carbonization temperature. Nonetheless, AC has an exceptionally high $R$ value. This is the first evidence of the more disordered graphitic microstructure of BGCs as comparing to AC. Figure 1e shows the Raman spectra of BGCs and AC. All spectra have characteristic D and $\mathrm{G}$ bands, which, respectively, represents the defective graphitic microstructure and the $s p^{2}$-hybridized graphitic domains [46, 59]. Therefore, the degree of graphitic disorder 

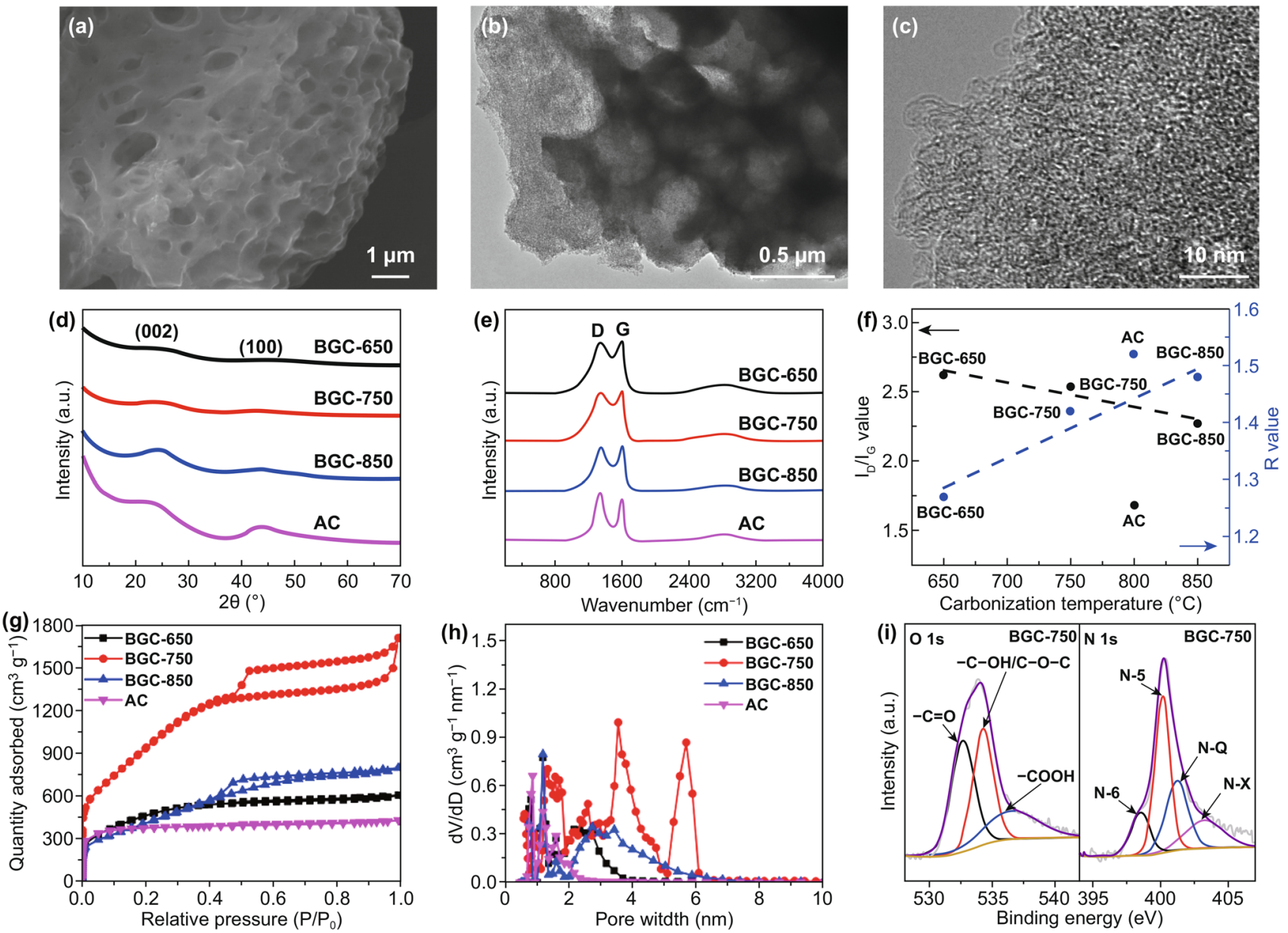

Fig. 1 a SEM micrograph of BGC-750. b TEM micrograph of BGC-750. c High-resolution TEM micrograph of BGC-750. d XRD patterns of BGCs and AC. e Raman spectra of BGCs and AC. f $I_{\mathrm{D}} / I_{\mathrm{G}}$ and $R$ values of BGCs and AC. $\mathbf{g}$ Nitrogen adsorption-desorption isotherms of BGCs and AC. $\mathbf{h}$ The corresponding pore size distributions. $\mathbf{i}$ O1s and N1s XPS spectra of BGC-750

and the defect concentration can be quantitatively evaluated by the intensity ratio of the two bands (i.e., $I_{\mathrm{D}} / I_{\mathrm{G}}$ ) [60]. As demonstrated in Fig. S3, the $I_{\mathrm{D}} / I_{\mathrm{G}}$ values were calculated based on the integral areas under curves. The large $I_{\mathrm{D}} / I_{\mathrm{G}}$ values of BGCs (Table S1) indicated the high degree of disorder and large population of defects in their graphitic lattices [43, 60, 61]. As shown in Fig. 1f, the $I_{\mathrm{D}} / I_{\mathrm{G}}$ also fits into a linear relationship with carbonization temperature. AC has a distinctly lower $I_{\mathrm{D}} / I_{\mathrm{G}}$ value that largely deviated from the BGC line. Both $R$ and $I_{\mathrm{D}} / I_{\mathrm{G}}$ values reveal that BGCs have larger degree of disorder containing much higher population of defects than the routine active carbons. We claim that the unique synthesis procedure aforementioned for BGC plays crucial role in creating such a special carbon tissue.

To characterize the porous structures of BGCs and AC, nitrogen adsorption/desorption isotherms analysis was performed. In Fig. 1g, the BGCs and AC present a typical type IV and I adsorption/desorption isotherms, respectively. For BGCs, the sharp rise of gas adsorption at relatively low pressure range $\left(P / P_{0}<0.01\right)$ and the continuous increase at medium pressure range $\left(0.1<P / P_{0}<0.5\right)$ are due to the existence of the micropores. The distinct hysteresis loop at the pressure range of $0.5-0.95$ is reflective of mesoporosity [ 49 , 62]. Specific to BGC-750, a slight rise at the high pressure range $\left(0.95<P / P_{0}<0.99\right)$ can be observed, which proves the existence of the macropores [63], whereas for AC, the platform occupying the whole pressure region of the isotherm indicates that the porosity is mainly composed of micropores [64]. These observations are in line with the SEM and TEM results. As shown in Table S1, the temperature significantly alters the Brunauer-Emmett-Teller (BET) surface areas and pore volumes of BGCs. At lower temperature of $650{ }^{\circ} \mathrm{C}$, 
the activation effect is too weak to generate massive pores, leading to the low surface area and pore volume for BGC650 , whereas the high temperature of $850{ }^{\circ} \mathrm{C}$ accelerates the graphitization which can seal the micropores and small mesopores [57, 65]. The optimized temperature of $750{ }^{\circ} \mathrm{C}$ maximizes the templating/activating effect and hence leads into the highest surface area and pore volume of 3657.5 and $2.428 \mathrm{~cm}^{3} \mathrm{~g}^{-1}, 2.9$ and 4.5 times the values of commercial AC. Figure $1 \mathrm{~h}$ displays the pore size distribution of BGCs and AC. AC is almost mesopore free, while BGCs possess both micro- and meso-porosities. BGC-750 has distinct mesoporosity with diameters of $2.5,3.5$ and $5.7 \mathrm{~nm}$. Combining with the micro-/meso-pores and macro-size voids, BGC-750 exhibits a favorable hierarchical porous architecture.

The surface chemistries of the carbons were investigated by X-ray photoelectron spectroscopy (XPS). As expected, the protein-rich precursor results into heteroatom-doped BGCs (Fig. S4a and Table S1). BGC-750 has moderate contents of both nitrogen (2.28 at\%) and oxygen (5.72 at\%) among BGCs; nonetheless, the highest surface area significantly magnifies the surficial heteroatom moieties exposed to electrolyte. The heteroatom information is also revealed in the high-resolution $\mathrm{C} 1 s$ spectra. Per Fig. S4b-e, the components of $\mathrm{C}=\mathrm{C} / \mathrm{C}-\mathrm{C}, \mathrm{C}-\mathrm{O} / \mathrm{C}-\mathrm{N}, \mathrm{C}=\mathrm{O}$, and $\mathrm{COOH}$ could be clearly discriminated $[64,66]$. The deconvolution of BGC$750 \mathrm{O} 1 s$ and $\mathrm{N} 1 s$ spectra is shown in Fig. 1i. The three peaks in $\mathrm{O} 1 s$ represent quinone-type groups $(\mathrm{C}=\mathrm{O}, \mathrm{O}-\mathrm{I})$, phenol groups/ether groups $(\mathrm{C}-\mathrm{OH} / \mathrm{C}-\mathrm{O}-\mathrm{C}, \mathrm{O}-\mathrm{II})$ and carboxylic groups (COOH, O-III) [67]. For N $1 s$, the four peaks present pyridinic- $\mathrm{N}(\mathrm{N}-6)$, pyrrolic- $\mathrm{N}(\mathrm{N}-5)$, quaternary-N (N-Q) and oxidized $\mathrm{N}(\mathrm{N}-\mathrm{X})$, respectively $[63,67,68]$. Other BGCs exhibit identical functional group configurations (Fig. S5), but there are diversities in the relative ratios of different oxygen and nitrogen species as a result of temperature change (Table S2). For BGC-750, O-I and N-5 occupy the largest proportions, which are $40.05 \%$ and $40.81 \%$ of all oxygen and nitrogen groups. For comparison, commercial $\mathrm{AC}$ is oxygen containing but totally nitrogen free.

\subsection{Electrochemical Performance of BGC- and AC-Based Zinc Ion Capacitors}

We constructed aqueous zinc ion capacitors by coupling the BGCs, AC as cathodes and zinc foils as anodes. $\mathrm{Zn}\left(\mathrm{CF}_{3} \mathrm{SO}_{3}\right)_{2}$ aqueous solution $(3 \mathrm{M})$ was utilized as the electrolyte, which ensures high $\mathrm{Zn}$ plating/stripping roundtrip efficiency in the system [30]. Figure 2a shows the cycling voltammetry (CV) curves of BGCs and AC-based zinc ion capacitors at $20 \mathrm{mV} \mathrm{s}^{-1}$. All the curves exhibit near-rectangular shapes in the voltage window of $0.1-1.8 \mathrm{~V}$ with negligible evidence of oxygen or hydrogen evolution side reactions. Some sub-structures in the CV curve, for instance, the small cathodic humps at 1.0/1.2 V, are reflective of certain redox processes involved [69]. As shown in Fig. S6, the near-rectangular shape of CV curve maintained well for BGC-750 as the scan rate increased to $500 \mathrm{mV} \mathrm{s}^{-1}$, while severe distortions appeared for other BGCs and AC. This phenomenon is a clear evidence of the more facile ion transport kinetics in BGC-750 than that of in others, which is largely benefited from the wide-open hierarchical porosity $[62,64,70]$. The galvanostatic charge-discharge (GCD) tests were conducted at current densities from 0.5 to $100 \mathrm{~A}$ $\mathrm{g}^{-1}$. Figure $2 \mathrm{~b}$ exhibits the obtained GCD profiles at $1 \mathrm{~A} \mathrm{~g}^{-1}$. The symmetrical quasi-triangular shape of the profiles is in line with the $\mathrm{CV}$ curves and also demonstrates the outstanding Coulombic efficiency (CE) [69]. The IR drop reflects the resistance of charge transfer in the electrode. As shown in Fig. S7 and Table S3, the IR drop values of BGC-750 are comparable to that of the highest graphitized BGC-850, distinctly lower than BGC-650 and AC. In addition, the IR drop of all the samples increased at higher current density resulted from the higher charge transfer resistance.

Figure $2 \mathrm{c}$ includes the gravimetric capacities of BGCs and AC cathodes at various current densities. The GCD profiles for first three cycles of these electrodes are shown in Fig. S8. In these initial cycles, the charge capacities are typically larger than discharge capacities. This phenomenon and the resulted Coulombic efficiency lower than 100\% (Fig. S9) are largely due to the side reaction of oxygen evolution [30, 71]. The measurements were taken at unprecedented high rates of 200-400 C (50-100 $\left.\mathrm{A} \mathrm{g}^{-1}\right)$. BGC-750 performs best throughout the whole rate range. Remarkably, maximum capacity of $257 \mathrm{mAh} \mathrm{g}^{-1}$ was obtained at starting rate of $2 \mathrm{C}$, and capacities of 126,99 and $72 \mathrm{mAh} \mathrm{g}^{-1}$ were obtained at rates of $80 \mathrm{C}, 200 \mathrm{C}$ and $400 \mathrm{C}$, respectively. In addition, the gravimetric capacitances of BGCs and $\mathrm{AC}$ are calculated by integrating the enclosed area between discharge curves and the horizontal time axis (Fig. S10). The equation utilized is listed in the supporting information. These extreme current densities were never been employed in our previous zinc-air or compound cathodes-based zinc ion batteries $[72,73]$. The 

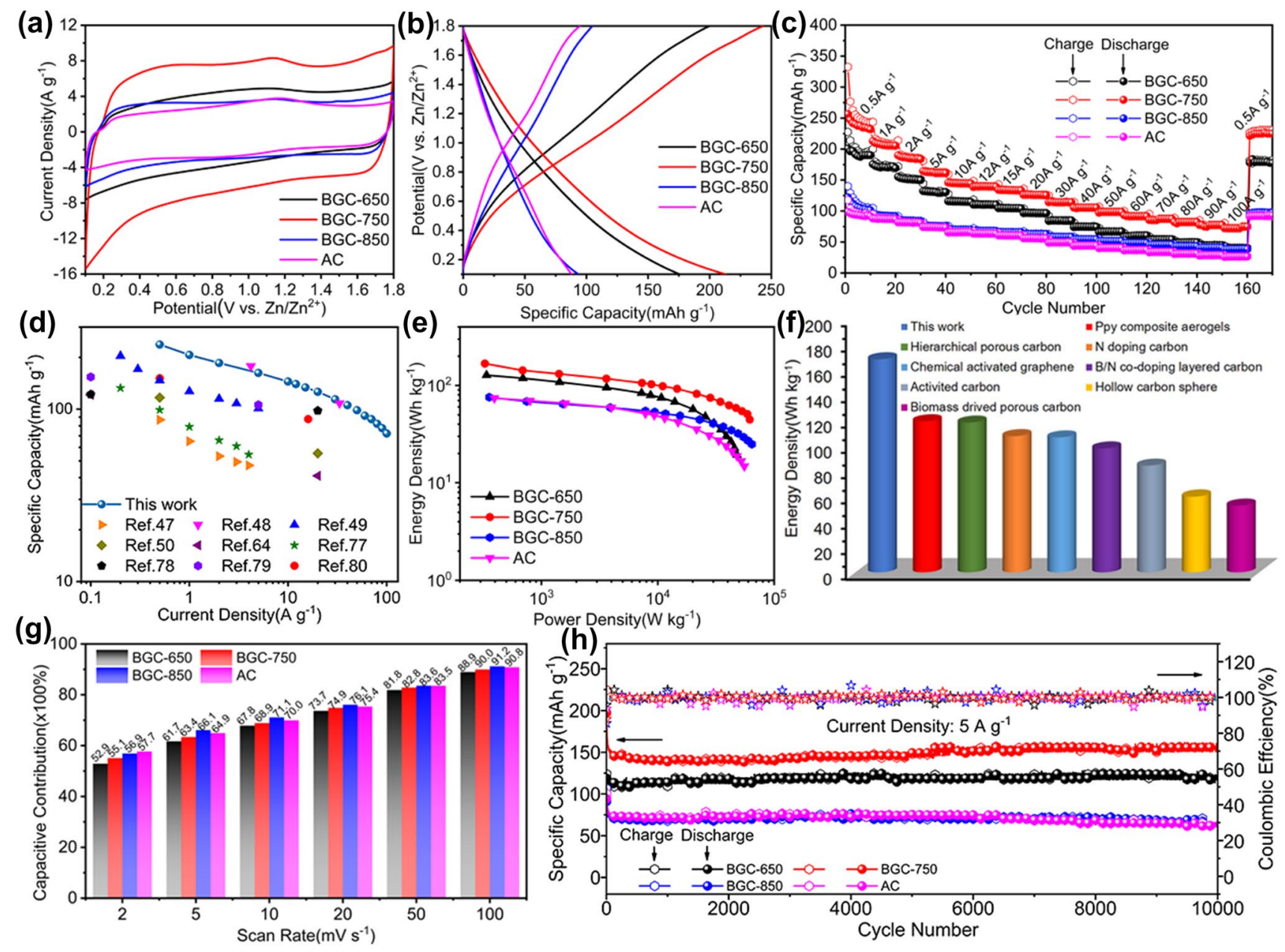

Power Density $\left(\mathrm{W} \mathrm{kg}^{-1}\right)$

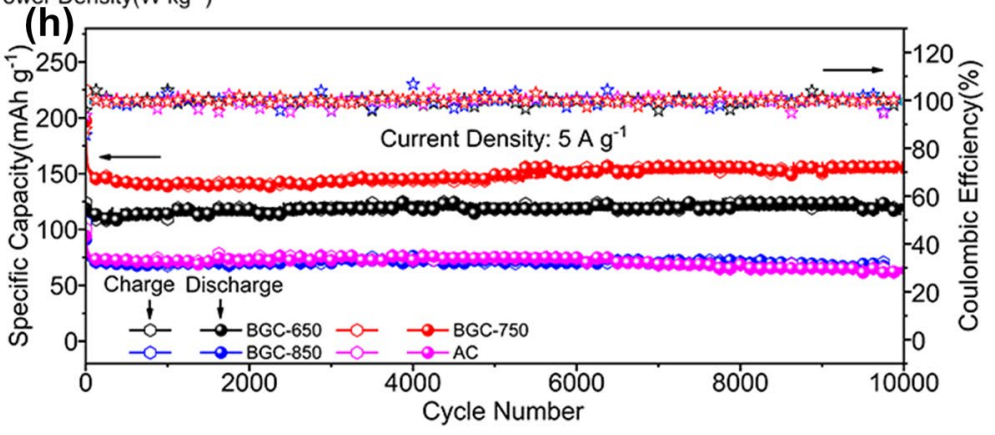

Fig. 2 Electrochemical performance of BGCs and AC cathodes-based zinc ion capacitors. a CV curves at $20 \mathrm{mV} \mathrm{s}^{-1}$. b Galvanostatic chargedischarge profiles at $1 \mathrm{~A} \mathrm{~g}^{-1}$. c Specific capacities at various current densities. d Rate performance comparison of BGC-750-based zinc ion capacitors versus literature reported values. e Ragone plot of BGCs and AC-based zinc ion capacitors. f Maximum energy density of BGCs versus the state-of-the-art carbon cathodes. $\mathbf{g}$ Normalized contribution ratio of capacitive capacities at different scan rates. $\mathbf{h}$ Cyclabilities of BGCs and $\mathrm{AC}$ at $5 \mathrm{~A} \mathrm{~g}^{-1}$

capacities of the BGC-650 and BGC-850 cathodes are lower than those of BGC-750 with BGC-850 as the more inferior one. AC has the lowest surface area and degree of graphitic disorder. Yet the high content of microporosity (i.e., $87.83 \%$ of the total pore volume) of $\mathrm{AC}$ is expected to endow higher utilization of the surface area and heteroatomic/defective sites, because the wall of microporosity is probably more favorable for charge adsorption in capacitors than that of meso-/macroporosity [74, 75]. As a result, the capacities of $\mathrm{AC}$ are only slightly lower than those of BGC-850 at all current densities. Given the moderate content of heteroatom and degree of graphitic disorder for BGC-750, this comparison reveals that the surface area and porosity structure are more important in determining the specific capacities of the BGC cathode. This phenomenon to some extent indicates that the charge storage should largely be a surficial process, since the much higher surface area of BGC-750 (around twice of other BGCs) can expose much more active sites on the cathode surface. Also, the hierarchical porous structure consisted of open macropores, interconnected mesopores and macropores can effectively facilitate the ion diffusion, which endows the cathode with excellent capacity retention at the extreme rates $[46,47,50,76]$. The more facile ion transport in BGC-750 can also be supported by the electrochemical impedance spectroscopy (EIS) analysis. Figure S11a shows the Nyquist plots of BGCs and AC, where the semicircular curves in the high-frequency region refer to the charge transfer resistance $\left(R_{\mathrm{ct}}\right)$, while the slope lines in the low-frequency range link 
to the Warburg impedance $\left(Z_{\mathrm{W}}\right)$ [36]. The equivalent circuit employed for the data analysis is shown in Fig. S11b, where $R_{\mathrm{e}}$ and CPE denote the total ohmic resistance and the constant phase element, respectively. The BGC-750 exhibits the smallest $R_{\mathrm{ct}}(67.6 \Omega)$ than BGC-650 (71.3 $\Omega$ ), BGC$850(96.2 \Omega)$ and AC (124.1 $\Omega$ ). Moreover, BGC-750 curve exhibits a nearly vertical straight line at the ion diffusion controlled low-frequency range, which is reflective of the unimpeded ion transportation [48, 49].

It is instructive to compare the electrochemical performance of BGC-750 with that of the state-of-the-art carbon cathodes in hybrid zinc ion capacitors. Table S4 summarizes the properties of the reported carbon-based zinc ion capacitors in literature by far, including electrolyte, cell configuration, capacity, energy/power and cyclability. First, the rate performance of BGC-750 outperforms most existing carbon cathodes (Fig. 2d) [47-50, 64, 77-80]. After counting into the working potential, the Ragone plots of the BGCs and AC-based zinc ion capacitors are shown in Fig. 2e (The calculation methods used for calculation are in Supporting Information). The cell with BGC-750 cathode delivers a specific energy density of $168 \mathrm{Wh} \mathrm{kg}^{-1}$ at a power density of $327 \mathrm{~W} \mathrm{~kg}^{-1}$. At an extremely high power of $61,700 \mathrm{~W} \mathrm{~kg}^{-1}$, energy density of $45 \mathrm{Wh} \mathrm{kg}^{-1}$ still remains. According to the side-by-side comparison in Fig. 2f, this energy level is substantially superior to other carbon cathodes-based zinc ion capacitors, for instance activated carbon [64], chemical activated graphene [30], heteroatoms doping carbons [48, 50], hierarchical porous carbons [47, 49], polymer aerogels [80], etc.

An effective approach to understand the intrinsic kinetics of the charge storage in electrodes is to mathematically analyze the change of active current as a function of potential scan rate. The relationship between the two variables may be expressed as $i=a v^{b}$, where $i, v, a$, and $b$ are on behalf of the current, scan rate and two adjustable constants [81]. The linear relationship $(b=0.5)$ indicates a diffusion limited process. Conversely, a $b$ value of 1 originates from a surface capacitive behavior that dominates the charge storage process $[82,83]$. The values of current $(i)$ and scan rate (v) were read from the CV curves (Fig. S12), and the indicative $b$ value can be represented by the slope of $\log i$ versus $\log v$ profiles (Fig. S13). The calculated $b$ values of cathodic and anodic peaks of BGCs and AC are 0.91-0.99 and $0.85-0.92$, respectively. These $b$ values indicate that the charge storage processes in BGC cathodes are capacitive in nature occurring on the carbon surface with negligible ion diffusion action in carbon bulk, which agrees with the aforementioned observation. Meanwhile, the contribution of the capacitive charge storage was quantitatively calculated via dividing the current response into two parts (proportional to $v^{1 / 2}$ and $v$ ) as following equation: $i=k_{1} v+k_{2} v^{1 / 2}$ [63]. Variables $k_{1}$ and $k_{2}$ represent the proportions of the capacitive and non-capacitive contributions. As shown in Fig. S14, the capacitive contributions of BGC-650, -750 and -850 at a scan rate of $10 \mathrm{mV} \mathrm{s}^{-1}$ are $67.8 \%, 68.9 \%$ and $71.1 \%$. In addition, the proportion of the capacitive contribution increases at high scan rates, exceeding $91 \%$ at $100 \mathrm{mV} \mathrm{s}^{-1}$ (Fig. 2g). The high proportion of capacitive charge storage is favorable for achieving high power AZBs [84, 85]. Furthermore, as shown in Fig. $2 \mathrm{~h}$, the BGCs cathodes also exhibit excellent cyclability upon extremely long cycling by virtue of such a capacitive ion storage process absent of bulk ion intercalation/extraction, which inevitably leads to volume change and interfacial resistance increase. Also, the GCD profiles for first three cycles are shown in Fig. S15.

\subsection{Charge Storage Mechanism Investigation and Active Sites Identification}

To explore the reasons for the electrochemistry and better understand the charge storage mechanisms of carbon cathodes in zinc ion capacitors, we performed systematic experiments and calculations to investigate the capacitive charge storage behavior of BGCs. First, XPS was employed to characterize the surface components at different charge and discharge states. To rule out the interference of fluorine in PVDF, we utilized sodium carboxymethyl cellulose (CMC) as the binder in the ex situ electrodes. Figure S16 displays the galvanostatic profiles and rate capacities of BGC-750 electrode using CMC binder. As comparing to Figs. $2 \mathrm{c}$ and S8b, the changing of binder from PVDF to $\mathrm{CMC}$ made negligible effect on the electrochemical performance of BGC-750. As shown in Fig. 3b, c, seven critical voltage points were selected in the first discharging and the second charging. Elements of C, O, F, S, N, Zn are detected in the XPS survey spectra, which exhibit distinct fluctuations in contents at different charge/discharge states. The signal of $\mathrm{Zn} 2 p$ and $\mathrm{F} 1 s$ is the descriptors of reflect to track the movement of $\mathrm{Zn}^{2+}$ cation and $\mathrm{CF}_{3} \mathrm{SO}_{3}{ }^{-}$anion in the system. The typical open-circuit voltage of as-assembled zinc ion 
capacitor is around 1.1 V. As shown in Fig. 3e, upon the first discharge, the intensity of $\mathrm{Zn} 2 p$ signal gradually increased from state $a$ (full charge state, $1.8 \mathrm{~V}$ ) to state $d$ (full discharge state, $0.1 \mathrm{~V}$ ), which clearly reveals the $\mathrm{Zn}^{2+}$ cation adsorption on BGC surface. The high intensity of $\mathrm{Zn} 2 p$ in spectrum $d$ indicates the large amount of $\mathrm{Zn}^{2+}$ accumulated on the cathode upon the deepest discharging. Meanwhile, the $\mathrm{F} 1 s$ signal corresponding to the $\mathrm{CF}_{3} \mathrm{SO}_{3}{ }^{-}$anion displays gradual attenuation upon discharge and thoroughly disappears at $0.67 \mathrm{~V}$ (point $c$ ). This phenomenon indicates the $\mathrm{CF}_{3} \mathrm{SO}_{3}{ }^{-}$anions desorption from BGC surface. In the reverse charging process (Fig. 3f), the $\mathrm{F} 1 s$ signal starts to reappear after point $f(1.23 \mathrm{~V})$ instead of from the primary $d, e$ points. Therefore, the adsorption of $\mathrm{CF}_{3} \mathrm{SO}_{3}{ }^{-}$anions is discovered to occur only at high voltage region. The attenuation of $\mathrm{Zn} 2 p$ peaks starts from the lowest voltage of $0.1 \mathrm{~V}$ and lasts the whole $1.7 \mathrm{~V}$ voltage range, indicating that the $\mathrm{Zn}^{2+}$ desorption could occur at any potential. It is worth noting that trace $\mathrm{Zn}^{2+}(<0.1$ at $\%)$ is detected at full-charge states $(a \& g)$, which may be attributed to the residue $\mathrm{Zn}^{2+}$ trapped in carbon sub-surface. We also conducted the same ex situ characterization on the AC baseline. The resulted XPS survey spectra are shown in Fig. S17. The trends of increasing in $\mathrm{Zn}^{2+}$ signal upon discharging ( $a$ to $c$ to $d$ ) and decreasing in $\mathrm{Zn}^{2+}$ signal upon charging ( $d$ to $e$ to $g$ ) agree well with the observation in Fig. 3e, f, proving the reversible $\mathrm{Zn}^{2+}$ ions adsorption on AC. The very weak $\mathrm{F} 1 s$ signals in the fully charge states of $a$ and $g$ indicate the restricted anion adsorption in AC. Considering the large spatial dimensions of $\mathrm{CF}_{3} \mathrm{SO}_{3}{ }^{-}$anion [86] and the majority of microporosity with size below $1 \mathrm{~nm}$ in $\mathrm{AC}$, it is expected that there is severe steric hindrance for $\mathrm{CF}_{3} \mathrm{SO}_{3}{ }^{-}$anion diffusion within microporosity which increases the voltage polarization of $\mathrm{CF}_{3} \mathrm{SO}_{3}{ }^{-}$adsorption and leads to very small amount of anion adsorption on AC at cutoff voltage of $1.8 \mathrm{~V}$. We further analyzed the high-resolution $\mathrm{C} 1 s$ spectra of BGC-750 to understand the possible charge transfer process involved in the aforementioned adsorption/desorption (Fig. 3g). Notably, the spectra show a pronounced $\mathrm{C}-\mathrm{O}-\mathrm{Zn}$ bonding component at $287.4 \mathrm{eV}$, which is resulted from the Faradic reaction between $\mathrm{Zn}^{2+}$ and $\mathrm{C}-\mathrm{OH}$ or $\mathrm{C}=\mathrm{O}[48,87,88]$. The evolution of the peak intensity ratio of $\mathrm{C}-\mathrm{O}-\mathrm{Zn}$ to $\mathrm{C}-\mathrm{OH}$ and $\mathrm{C}-\mathrm{O}-\mathrm{Zn}$ to $\mathrm{C}=\mathrm{O}$ was evaluated and is plotted in Fig. $3 \mathrm{~h}$. The data indicate the increased $\mathrm{C}-\mathrm{O}-\mathrm{Zn}$ bonds and decreased $\mathrm{C}-\mathrm{OH} /$ $\mathrm{C}=\mathrm{O}$ groups upon discharge, and this well-defined trend is reversible in the charge process. This observation reveals a representative oxygen groups involved charge transfer process that contributes capacity. More comprehensive analysis was conducted by the aid of first principle calculation as shown below.

Based on the preceding analyses, we claim that the BGC cathode undergoes a reversible dual-ion adsorption process in zinc ion capacitors. Both the cation and anion act as charge carriers for energy storage, yet they function at different voltage regions (Fig. 3a, d). As discharging from 1.8 to $1.23 \mathrm{~V}$, the desorption of anion and the adsorption of cation take place simultaneously. As discharged below $0.67 \mathrm{~V}$, the anion desorption completes together with the continuing cation adsorption. The charge storage below $0.67 \mathrm{~V}$ is simply responsible by the cations. In the charging process, the dual-ion adsorption follows the opposite path of the discharging. The majority of the cation desorption distributes in the low voltage. The anion adsorption occurs only as the cathode enters the high voltage region.

To determine the specific active sites for the dual-ion adsorption in the BGC cathodes, we calculated the relative adsorption energy $\left(\Delta E_{\mathrm{a}}\right)$ values of $\mathrm{Zn}^{2+}$ cation and $\mathrm{CF}_{3} \mathrm{SO}_{3}{ }^{-}$anion at the atomic heterogeneous sites and defective sites as comparing to that of on flawless graphene surface (Table S5). As revealed by XPS, Raman and BET results, BGCs are rich in heteroatoms and defects, the populations of which are significantly amplified by the immense surface areas. For the heteroatom sites, we choose nitrogen-5, -6 and oxygen-I, -II as the structure models. For the lattice defects, a representative defect of divacancy is employed for calculation $[89,90]$. An individual $\mathrm{Zn}^{2+}$ or $\mathrm{CF}_{3} \mathrm{SO}_{3}{ }^{-}$ion was placed close to each site, and the optimized geometry structure is ascertained in light of the calculated $\Delta E_{\mathrm{a}}$. As shown in Fig. $4 \mathrm{a}$, d, the $\Delta E_{\mathrm{a}}$ values of $\mathrm{Zn}^{2+}$ and $\mathrm{CF}_{3} \mathrm{SO}_{3}{ }^{-}$at $\mathrm{N}-5$ are -4.81 and $-3.75 \mathrm{eV}$, respectively, which are much higher than those on flawless graphene surface $(-0.02 \mathrm{eV},-1.29 \mathrm{eV}$, Fig. S18c, f). This indicates that $\mathrm{N}-5$ is active toward both cation and anion adsorption. Similar ion affinity is also observed for N-6 site (Fig. S18a, d). It was reported that $\mathrm{C}-\mathrm{O}-\mathrm{C}$-type groups are active in chemically adsorbing various alkali ions in organic systems [91-93]. Our calculation result indicates that these O-II sites are also capable for $\mathrm{Zn}^{2+}$ cation adsorption in aqueous system $\left(\Delta E_{\mathrm{a}}=-4.58 \mathrm{eV}\right)$. Remarkably, the negative charged $\mathrm{CF}_{3} \mathrm{SO}_{3}{ }^{-}$ion also exhibits a high $\Delta E_{\mathrm{a}}$ at O-II sites $\left(\Delta E_{\mathrm{a}}=-4.59 \mathrm{eV}\right)$. Certain electron-rich part of the $\mathrm{CF}_{3} \mathrm{SO}_{3}{ }^{-}$molecular may be functional for this interaction. 
(a)

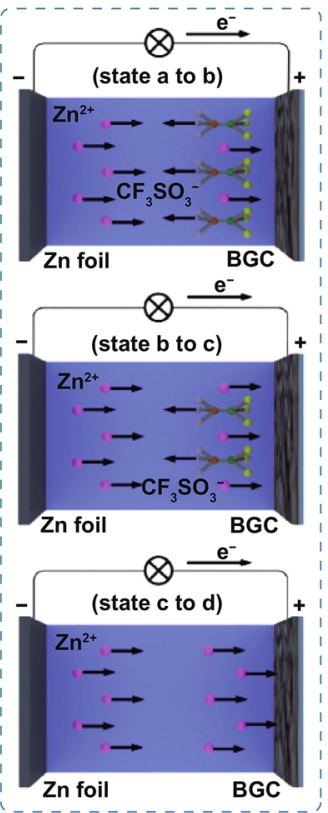

(b)

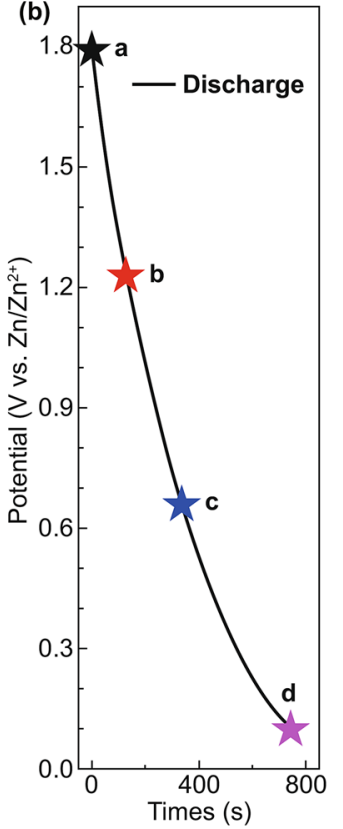

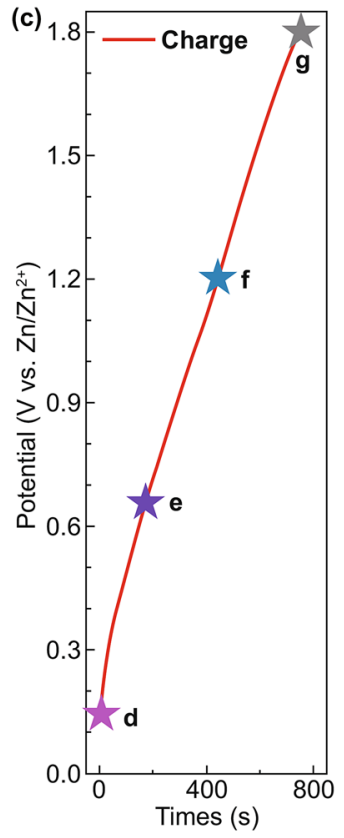

(d)

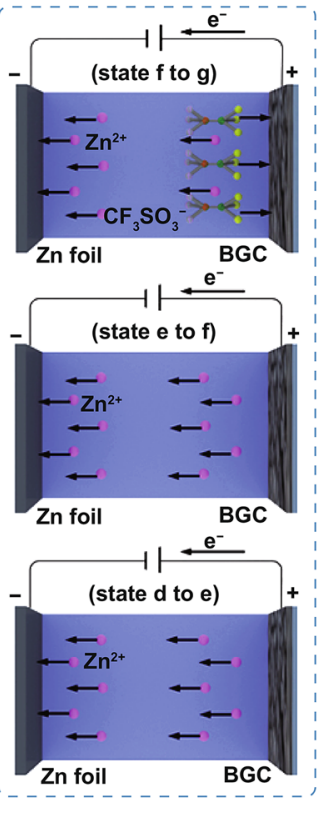

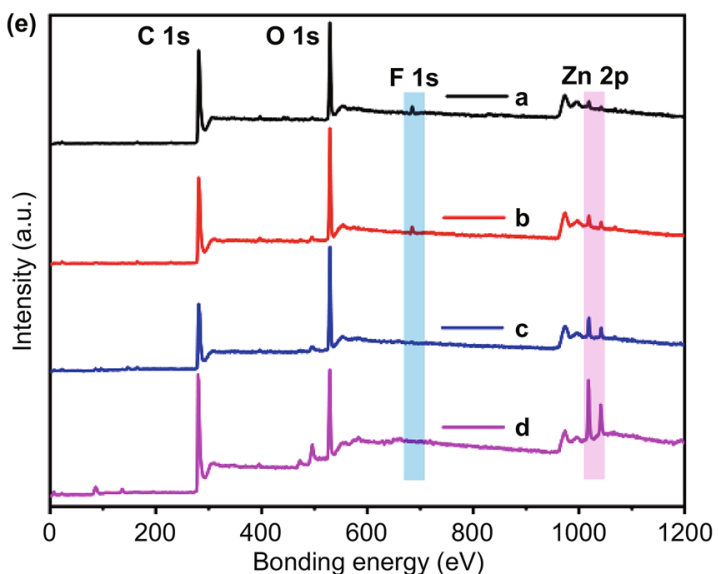
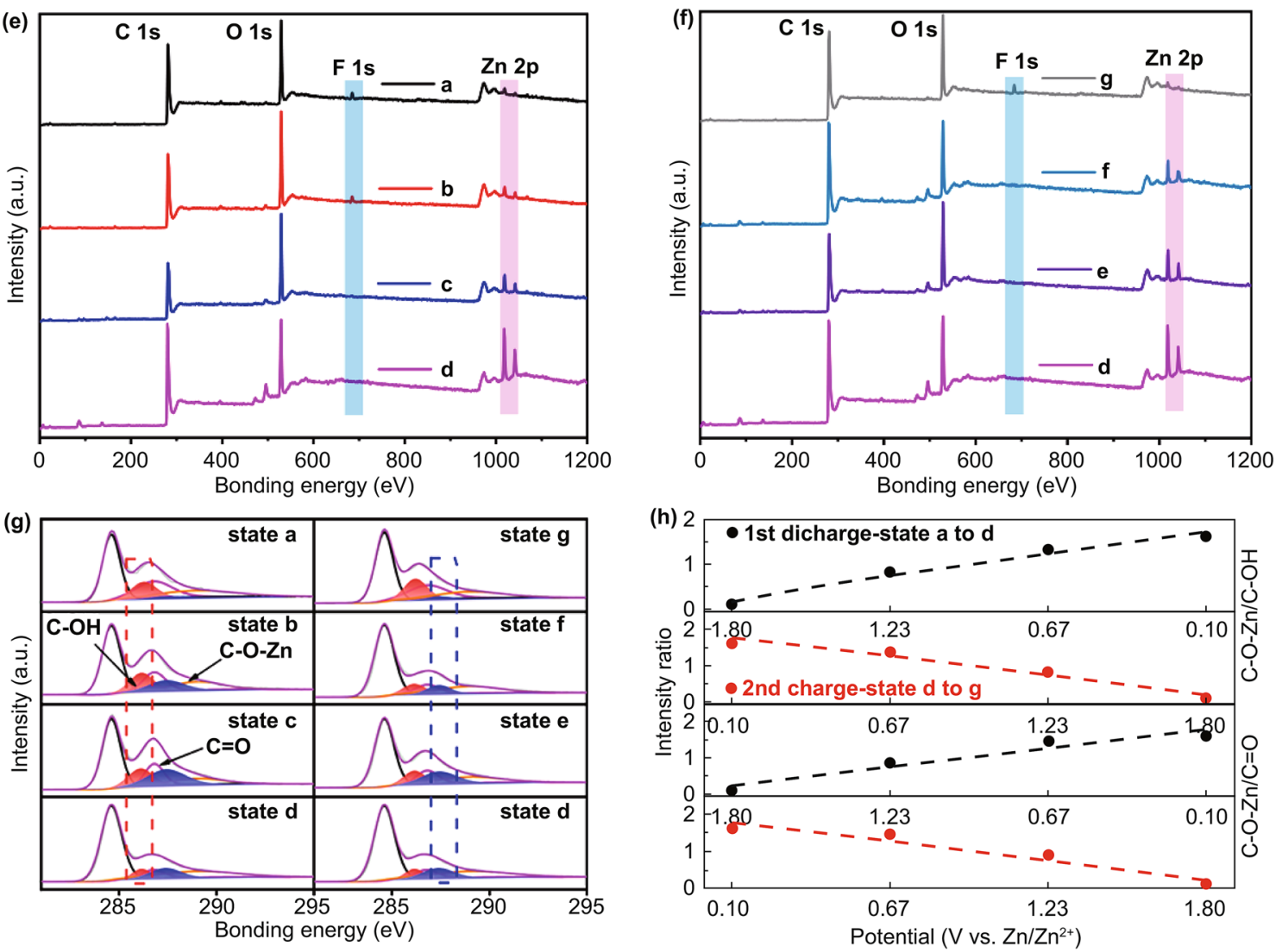

Fig. 3 a, d Schematic diagram of the cation and anion transportation during discharge/charge. $\mathbf{b}$, $\mathbf{c}$ The selected voltage points in the discharge/ charge curves of BGC-750 for ex situ characterization. e, $\mathbf{f}$ Ex situ XPS spectra at the selected states. $\mathbf{g}$ Ex situ C $1 s$ XPS spectra at the selected states. $\mathbf{h}$ The intensity ratio of $\mathrm{C}-\mathrm{O}-\mathrm{Zn} / \mathrm{C}-\mathrm{OH}$ and $\mathrm{C}-\mathrm{O}-\mathrm{Zn} / \mathrm{C}=\mathrm{O}$ peaks according to $\mathbf{g}$ 

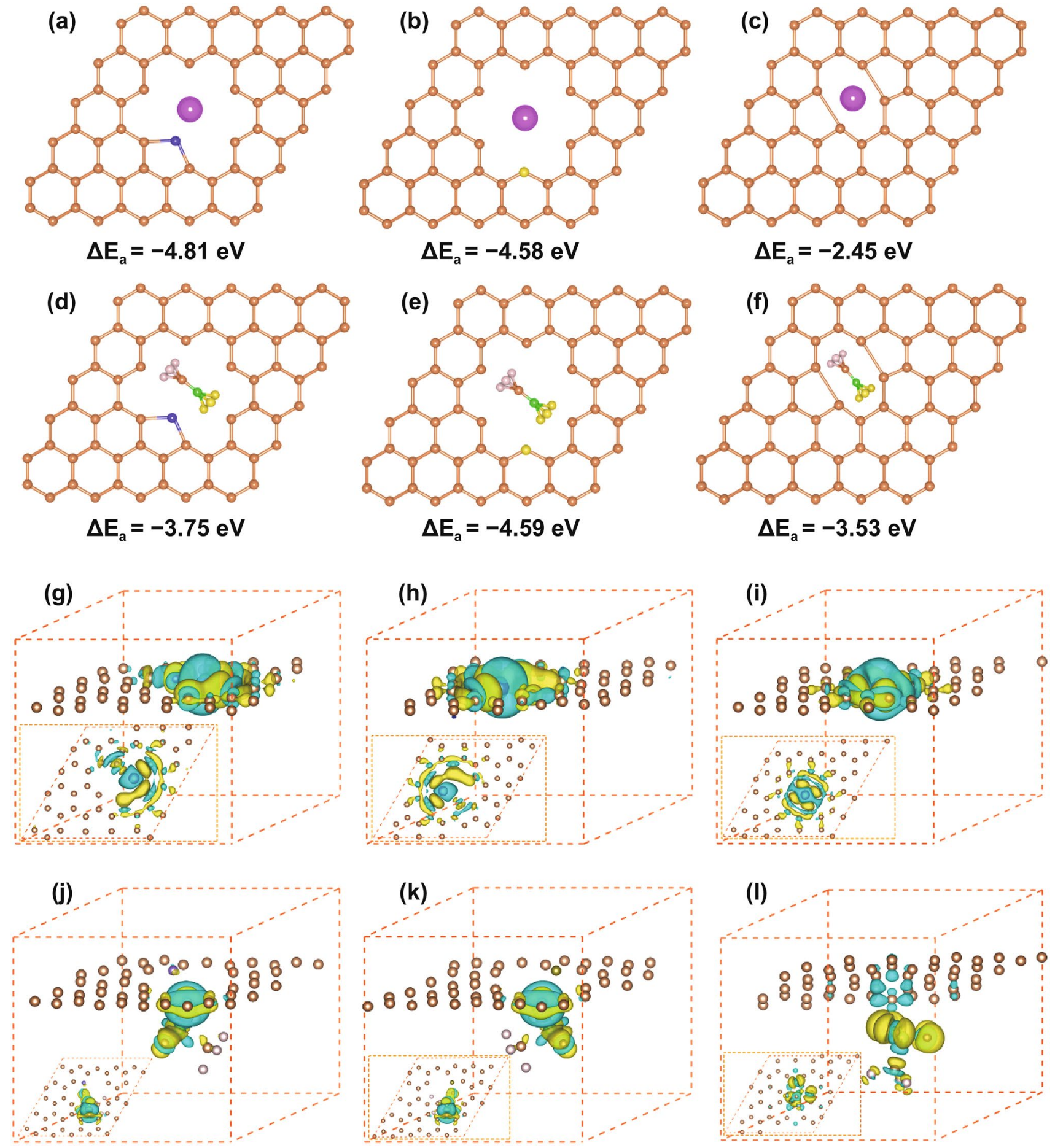

Fig. 4 Theoretical simulations of $\mathrm{Zn}^{2+} / \mathrm{CF}_{3} \mathrm{SO}_{3}{ }^{-}$-adsorption on different graphitic structures. The configurations and corresponding adsorption energy values of single $\mathrm{Zn}^{2+} / \mathrm{CF}_{3} \mathrm{SO}_{3}{ }^{-}$adsorbed at $\mathbf{a} / \mathbf{d} \mathrm{N}-5$, b/e O-II sites and $\mathbf{c} / \mathbf{f}$ divacancy sites. Side and top views (inserts) of electron density differences of $\mathrm{Zn}^{2+} / \mathrm{CF}_{3} \mathrm{SO}_{3}{ }^{-}$absorbed in the $\mathbf{g} / \mathbf{j} \mathrm{N}-5, \mathbf{h} / \mathbf{k}$ O-II sites and $\mathbf{i} / \mathbf{l}$ divacancy defect sites. Yellow and blue areas represent the increased and decreased electron density, respectively. Brown, purple, light yellow, green, gray, pink and blue balls represent $\mathrm{C}, \mathrm{N}, \mathrm{O}, \mathrm{S}, \mathrm{F}, \mathrm{Zn}, \mathrm{and} \mathrm{H}$ atoms, respectively. The iso-surfaces are the 0.002 electron bohr ${ }^{3}$ 
In addition, the $\Delta E_{\mathrm{a}}$ remains considerably high as $\mathrm{Zn}^{2+}$ / $\mathrm{CF}_{3} \mathrm{SO}_{3}{ }^{-}$was placed around $\mathrm{C}=\mathrm{O}$-type groups (O-I) (Fig. $\mathrm{S} 18 \mathrm{~b}, \mathrm{e})$. Divacancy is a typical lattice defect in carbon, which is resulted from the missing of two neighboring carbon atoms $[90,94,95]$. The divacancy defects can significantly generate electron redistribution, thus adsorbing the charged ions. For instance, the $\Delta E_{\mathrm{a}}$ of $\mathrm{Zn}^{2+}$ and $\mathrm{CF}_{3} \mathrm{SO}_{3}{ }^{-}$at the divacancy sites are -2.45 and $-3.53 \mathrm{eV}$, respectively, higher than the flawless graphene surface baseline (Fig. 4c, f). To confirm the formation of bonding between surficial sites and ions, we conducted the differential charge density analyses for the adsorption configurations. The increase of electron density in the intermediate domain between graphene sheet and ion is reflective of the charge transfer between the surficial sites and ions. As shown in Figs. 4g-1 and $\mathrm{S} 18 \mathrm{~g}-1$, there are net increases in charge density for both heteroatom (N-5/-6, O-I/-II) and divacancy sites, indicating occurrence of the chemical adsorption processes involving in Faradic charge transfer [96-98]. The comprehensive calculations reveal the capacitive dual-ion adsorption at the heteroatom moieties and lattice defects in BGCs, providing insight of the significantly improved AZB energy and power by virtue of advanced charge storage mechanism.

\subsection{Electrochemical Performance of Flexible Pouch-/ Cable-type AZB Devices}

One critical target of developing AZBs is to power the flourishing flexible and wearable electronic devices [47]. To verify the applicability of the BGC-based zinc ion capacitors as flexible power sources, we go steps further than the routine coin cell and fabricate quasi-solid-state pouch and cable-type cells. Figure 5a, b demonstrates the procedures of the pouch-type and cable-type cells fabrication. We first developed a gel polymer electrolyte (GPE) with PVA as the gel matrix and $\mathrm{ZnSO}_{4}$ as a neutral salt. According to our previous experience, GPE-based zinc-air batteries could be easily deteriorated by the fast water loss due to the open cell structure [99-101]. The cells in this work are free of this issue, because the PVA/ $/ \mathrm{ZnO}_{4}$ gel electrolyte performs steadily in the closed cells. For the pouch cells (Fig. 5a), the BGC-750 anchored carbon cloth, and the freestanding GPE film and zinc foil were layer-bylayer assembled into a sandwich-type structure followed by the air evacuation and firm packaging. The cable-type cell has a coaxial structure with BGC-750-loaded carbon fiber as the core and GPE/spiral zinc foil as the shells (Fig. 5b). Superior to the typical zinc wire-centered zinc-air cells, the cathode cores in our setups are well protected by the GPE/ zinc metal shells; hence, the typical active material loss is totally eliminated. The as-prepared pouch- and cable-type cells exhibit excellent flexibility upon various deformations without apparent sacrifice of electrochemical performance. For instance, the pouch-type cell can be easily bent $90^{\circ}$, rolled up to hollow circular column and folded $180^{\circ}$, at which states the cell maintains the pristine flat-shape electrochemistry in terms of voltage profiles, capacity and CE (Fig. 5c). Also for the cable-type cell (Fig. 5d), the deformation of U-shape curving, zigzag bending and even tightly knotting barely affect the performance of the cable-type cell, as revealed by the mostly overlapped GCD profiles. In addition, due to the practical mass loading and shape flexibility for fulfilling different application conditions, the pouch-type cell is the best configuration for evaluating the true practicability of a new battery system. Therefore, we also collected the specific capacities of the pouch-type cells at rate of 2-60 C. The corresponding energy/power densities were calculated and were compared with the coin cells side-by-side. The resulted data are plotted in Figs. 5e and S19. Remarkably, the two cell configurations display comparable performance. The slightly higher capacities of the pouch-cell are probably benefited from the commercial battery-level carbon cloth as the current collector which is better at minimizing the active particle agglomeration than the flat stainless steel foils in coin cell. Figure 5f, g demonstrates two samples of utilizing the pouch- and cable-type cells for wearable electronic devices. The pouch-type cell can be twisted around human wrists to power other wearable electronics (lighting LED bulbs as an example). The cable-type cells can be easily connected in series or parallel to multiply the voltage or current, which can be knitted into clothes for powering smart watches and other equipment. 
(a)

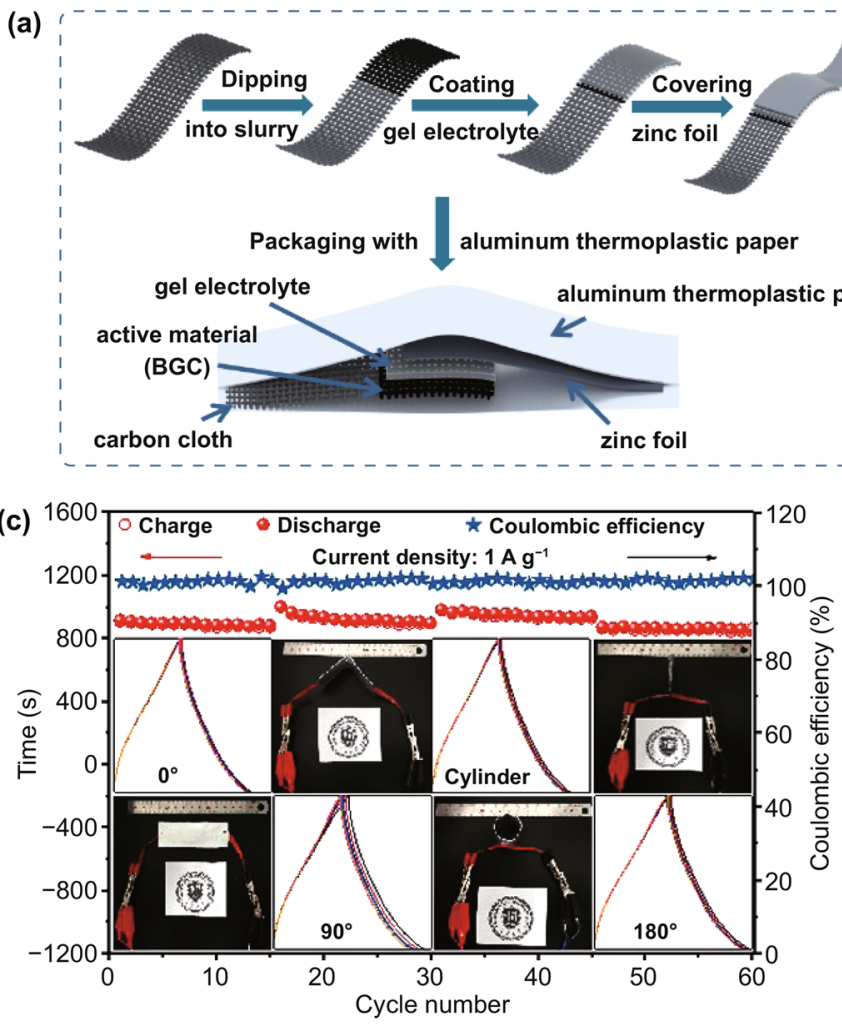

(e)

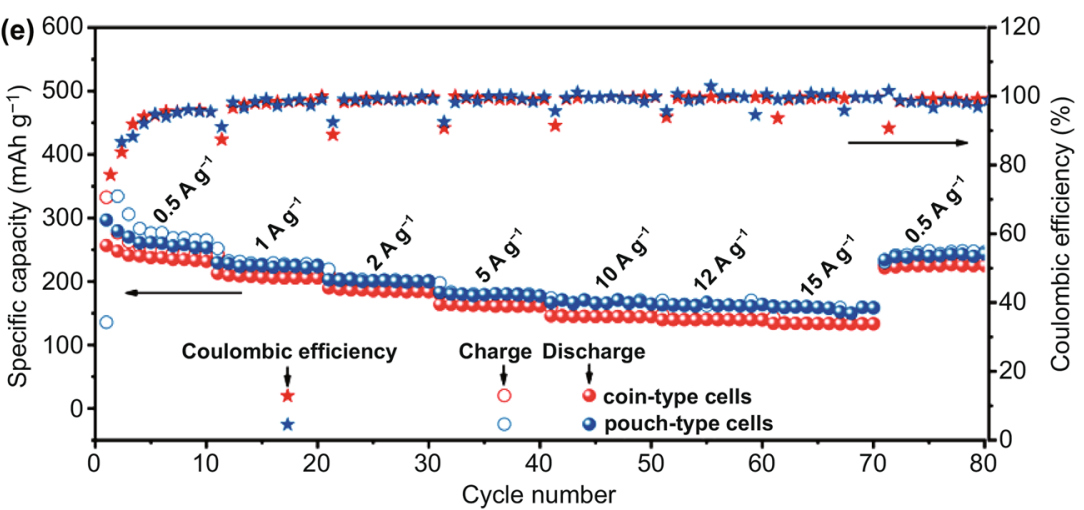

(d) (b)

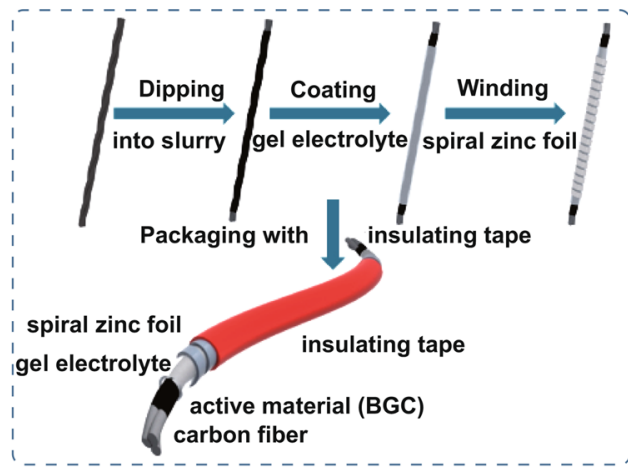

(c)

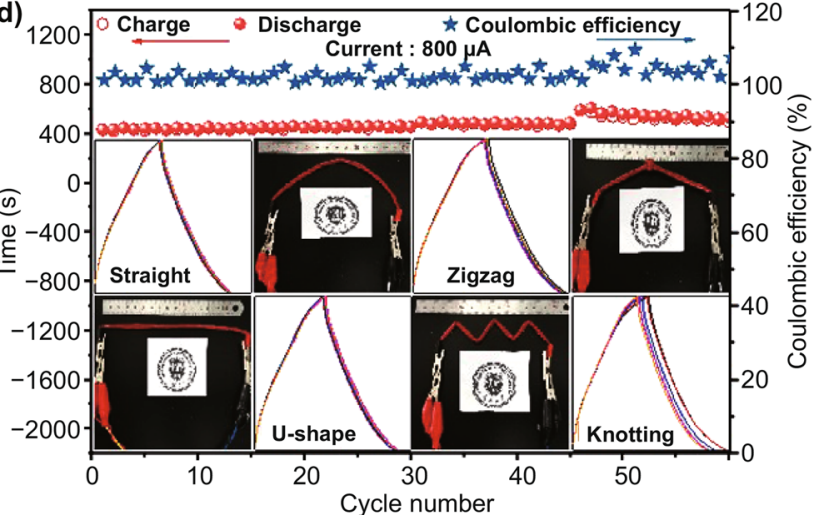

(f)

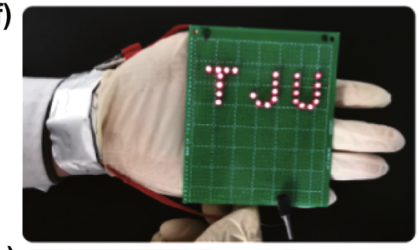

(g)

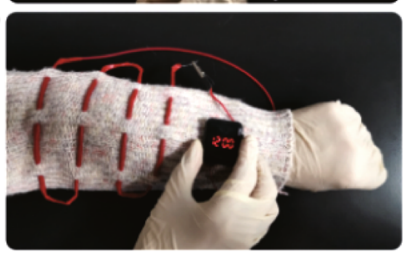

Fig. 5 a, b Schematic diagrams of pouch-type and cable-type quasi-solid-state zinc ion capacitors. Cycling performance of pouch-type cell c and cable-type cell $\mathbf{d}$ upon deformation. The inserts exhibit the optical images of the deformed cells and corresponding galvanostatic charge-discharge profiles. e Specific capacities at various current densities for coin cells and pouch-type cells. $\mathbf{f}$ Photograph of LED array powered by two pouch-type cells in series. $\mathrm{g}$ Photograph of a digital watch powered by four cable-type cells in series

\section{Conclusion}

To summarize, we employed a unique dual-ion adsorption mechanism in the carbon cathode for aqueous zinc-based batteries. Experiments and DFT calculations reveal that both the cation and anion function as charge carriers and are reversibly adsorbed at the heteroatom moieties and lattice defects on the carbon surface. The optimized BGC cathode possesses immense surface area, hierarchical porosity and defect-rich graphite tissue and hence maximizes the population of the electrochemically active sites for the reversible dual-ion adsorption. Quantitative analysis indicates that the dual-ion adsorption process is primarily contributed by capacitive charge storage and thus is kinetically facile. This enables the aqueous zinc-based battery to deliver unrivaled combination of high energy and power characteristics, reaching $168 \mathrm{Wh}$ 
$\mathrm{kg}^{-1}$ and $61,700 \mathrm{~W} \mathrm{~kg}^{-1}$, respectively. The BGC-based zinc ion capacitors are also extended to quasi-solid-state pouchand cable-type configurations. The flexible cells exhibit high reliability under various deformation conditions, serving as promising power sources for the wearable devices.

Acknowledgements J. D. greatly acknowledges the support from the National Natural Science Foundation of China (No. 52072257) and the financial support from the National Key Research and Development Program of China (No.: 2019YFE0118800). W. H. greatly acknowledges the support from the National Natural Science Foundation of China and Guangdong Province (No. U1601216). H. W. greatly acknowledges the support from the Shandong Provincial Key R\&D Plan and the Public Welfare Special Program, China (2019GGX102038), and the Fundamental Research Funds for the Central Universities (No. 201822008 and 201941010).

Open Access This article is licensed under a Creative Commons Attribution 4.0 International License, which permits use, sharing, adaptation, distribution and reproduction in any medium or format, as long as you give appropriate credit to the original author(s) and the source, provide a link to the Creative Commons licence, and indicate if changes were made. The images or other third party material in this article are included in the article's Creative Commons licence, unless indicated otherwise in a credit line to the material. If material is not included in the article's Creative Commons licence and your intended use is not permitted by statutory regulation or exceeds the permitted use, you will need to obtain permission directly from the copyright holder. To view a copy of this licence, visit http://creativecommons.org/licenses/by/4.0/.

Supplementary Information The online version of this article (https://doi.org/10.1007/s40820-021-00588-5) contains supplementary material, which is available to authorized users.

\section{References}

1. F. Wang, O. Borodin, T. Gao, X. Fan, W. Sun et al., Highly reversible zinc metal anode for aqueous batteries. Nat. Mater. 17, 543-549 (2018). https://doi.org/10.1038/s4156 3-018-0063-z

2. P. He, M. Yan, G. Zhang, R. Sun, L. Chen et al., Layered $\mathrm{VS}_{2}$ nanosheet-based aqueous $\mathrm{Zn}$ ion battery cathode. Adv. Energy Mater. 7, 1601920 (2017). https://doi.org/10.1002/ aenm. 201601920

3. N. Zhang, F. Cheng, Y. Liu, Q. Zhao, K. Lei et al., Cation-deficient spinel $\mathrm{ZnMn}_{2} \mathrm{O}_{4}$ cathode in $\mathrm{Zn}\left(\mathrm{CF}_{3} \mathrm{SO}_{3}\right)_{2}$ electrolyte for rechargeable aqueous $\mathrm{Zn}$-ion battery. J. Am. Chem. Soc. 138, 12894-12901 (2016). https://doi.org/10.1021/jacs.6b05958

4. C. Xu, B. Li, H. Du, F. Kang, Energetic zinc ion chemistry: the rechargeable zinc ion battery. Angew. Chem. Int. Ed. 51, 933-935 (2012). https://doi.org/10.1002/anie.201106307
5. B. Ji, W. Yao, Y. Tang, High-performance rechargeable zincbased dual-ion batteries. Sustain. Energy Fuels 4, 101-107 (2020). https://doi.org/10.1039/C9SE00744J

6. W. Sun, F. Wang, S. Hou, C. Yang, X. Fan et al., $\mathrm{Zn} / \mathrm{MnO}_{2}$ battery chemistry with $\mathrm{H}^{+}$and $\mathrm{Zn}^{2+}$ coinsertion. J. Am. Chem. Soc. 139, 9775-9778 (2017). https://doi.org/10.1021/ jacs.7b04471

7. D. Kundu, B.D. Adams, V. Duffort, S.H. Vajargah, L.F. Nazar, A high-capacity and long-life aqueous rechargeable zinc battery using a metal oxide intercalation cathode. Nat. Energy 1, 16119 (2016). https://doi.org/10.1038/nener gy.2016.119

8. H. Pan, Y. Shao, P. Yan, Y. Cheng, K.S. Han et al., Reversible aqueous zinc/manganese oxide energy storage from conversion reactions. Nat. Energy 1, 16039 (2016). https://doi. org/10.1038/nenergy.2016.39

9. L. Ma, S. Chen, D. Wang, Q. Yang, F. Mo et al., Superstretchable zinc-air batteries based on an alkaline-tolerant dual-network hydrogel electrolyte. Adv. Energy Mater. 9, 1803046 (2019). https://doi.org/10.1002/aenm.201803046

10. D. Ji, L. Fan, L. Li, S. Peng, D. Yu et al., Atomically transition metals on self-supported porous carbon flake arrays as binder-free air cathode for wearable zinc-air batteries. Adv. Mater. 31, 1808267 (2019). https://doi.org/10.1002/ adma.201808267

11. L. Ma, S. Chen, Z. Pei, Y. Huang, G. Liang et al., Single-site active iron-based bifunctional oxygen catalyst for a compressible and rechargeable zinc-air battery. ACS Nano $\mathbf{1 2}$, 1949-1958 (2018). https://doi.org/10.1021/acsnano.7b09064

12. J. Liu, C. Guan, C. Zhou, Z. Fan, Q. Ke et al., A flexible quasi-solid-state nickel-zinc battery with high energy and power densities based on 3D electrode design. Adv. Mater. 28, 8732-8739 (2016). https://doi.org/10.1002/adma.20160 3038

13. R. Wang, Y. Han, Z. Wang, J. Jiang, Y. Tong et al., Nickel@ nickel oxide core-shell electrode with significantly boosted reactivity for ultrahigh-energy and stable aqueous $\mathrm{Ni}-\mathrm{Zn}$ battery. Adv. Funct. Mater. 28, 1802157 (2018). https://doi. org/10.1002/adfm.201802157

14. N. Zhang, F. Cheng, J. Liu, L. Wang, X. Long et al., Rechargeable aqueous zinc-manganese dioxide batteries with high energy and power densities. Nat. Commun. 8, 405 (2017). https://doi.org/10.1038/s41467-017-00467-X

15. Y. Zeng, Y. Meng, Z. Lai, X. Zhang, M. Yu et al., An ultrastable and high-performance flexible fiber-shaped Ni-Zn battery based on a Ni-NiO heterostructured nanosheet cathode. Adv. Mater. 29, 1702698 (2017). https://doi.org/10.1002/ adma.201702698

16. X. Gao, H. Wu, W. Li, Y. Tian, Y. Zhang et al., $\mathrm{H}^{+}$-insertion boosted $\alpha-\mathrm{MnO}_{2}$ for an aqueous $\mathrm{Zn}$-ion battery. Small 16, 1905842 (2020). https://doi.org/10.1002/smll.201905842

17. W. Li, X. Gao, Z. Chen, R. Guo, G. Zou et al., Electrochemically activated $\mathrm{MnO}$ cathodes for high performance aqueous zinc-ion battery. Chem. Eng. J. 402, 125509 (2020). https:// doi.org/10.1016/j.cej.2020.125509 
18. M.H. Alfaruqi, V. Mathew, J. Song, S. Kim, S. Islam et al., Electrochemical zinc intercalation in lithium vanadium oxide: a high-capacity zinc-ion battery cathode. Chem. Mater. 29, 1684-1694 (2017). https://doi.org/10.1021/acs.chemm ater.6b05092

19. Y. Yang, Y. Tang, G. Fang, L. Shan, J. Guo et al., Li ${ }^{+}$intercalated $\mathrm{V}_{2} \mathrm{O}_{5} \cdot \mathrm{nH}_{2} \mathrm{O}$ with enlarged layer spacing and fast ion diffusion as an aqueous zinc-ion battery cathode. Energy Environ. Sci. 11, 3157-3162 (2018). https://doi.org/10.1039/ C8EE01651H

20. L. Zhang, I.A. Rodríguez-Pérez, H. Jiang, C. Zhang, D.P. Leonard et al., $\mathrm{ZnCl}_{2}$ "water-in-salt" electrolyte transforms the performance of vanadium oxide as a $\mathrm{Zn}$ battery cathode. Adv. Funct. Mater. 29, 1902653 (2019). https://doi. org/10.1002/adfm.201902653

21. M. Yan, P. He, Y. Chen, S. Wang, Q. Wei et al., Waterlubricated intercalation in $\mathrm{V}_{2} \mathrm{O}_{5} \cdot \mathrm{nH}_{2} \mathrm{O}$ for high-capacity and high-rate aqueous rechargeable zinc batteries. Adv. Mater. 30, 1703725 (2018). https://doi.org/10.1002/adma.201703725

22. X. Han, W. Zhang, X. Ma, C. Zhong, N. Zhao et al., Identifying the activation of bimetallic sites in $\mathrm{NiCo}_{2} \mathrm{~S}_{4} @ \mathrm{~g}-\mathrm{C}_{3} \mathrm{~N}_{4}-\mathrm{CNT}$ hybrid electrocatalysts for synergistic oxygen reduction and evolution. Adv. Mater. 31, 1808281 (2019). https://doi.org/10.1002/adma.201808281

23. M. Wu, Q. Wei, G. Zhang, J. Qiao, M. Wu et al., Fe/Co double hydroxide/oxide nanoparticles on N-doped CNTs as highly efficient electrocatalyst for rechargeable liquid and quasi-solid-state zinc-air batteries. Adv. Energy Mater. 8, 1801836 (2018). https://doi.org/10.1002/aenm.201801836

24. F. Liu, X. Zhang, X. Zhang, M. Liu, Q. Shao et al., Novel $\mathrm{Fe}_{3} \mathrm{C}$ nanoparticles encapsulated in bamboo-like nitrogendoped carbon nanotubes as high-performance electrocatalyst for zinc-air battery. J. Electrochem. Soc. 167, 060526 (2020). https://doi.org/10.1149/1945-7111/ab861d

25. M. Wu, G. Zhang, J. Qiao, N. Chen, W. Chen et al., Ultralong life rechargeable zinc-air battery based on high-performance trimetallic nitride and NCNT hybrid bifunctional electrocatalysts. Nano Energy 61, 86-95 (2019). https://doi. org/10.1016/j.nanoen.2019.04.031

26. Y. Huang, J. Mou, W. Liu, X. Wang, L. Dong et al., Novel insights into energy storage mechanism of aqueous rechargeable $\mathrm{Zn} / \mathrm{MnO}_{2}$ batteries with participation of $\mathrm{Mn}^{2+}$. NanoMicro Lett. 11, 49 (2019). https://doi.org/10.1007/s4082 0-019-0278-9

27. C. Xu, H. Du, B. Li, F. Kang, Y. Zeng, Reversible insertion properties of zinc ion into manganese dioxide and its application for energy storage. Electrochem. Solid-State Lett. 12, A61 (2009). https://doi.org/10.1149/1.3065967

28. N. Zhang, Y. Dong, M. Jia, X. Bian, Y. Wang et al., Rechargeable aqueous $\mathrm{Zn}-\mathrm{V}_{2} \mathrm{O}_{5}$ battery with high energy density and long cycle life. ACS Energy Lett. 3, 1366-1372 (2018). https ://doi.org/10.1021/acsenergylett.8b00565

29. J. Wang, J.-G. Wang, H. Liu, Z. You, C. Wei et al., Electrochemical activation of commercial $\mathrm{MnO}$ microsized particles for high-performance aqueous zinc-ion batteries. J. Power
Sources 438, 226951 (2019). https://doi.org/10.1016/j.jpows our.2019.226951

30. S. Wu, Y. Chen, T. Jiao, J. Zhou, J. Cheng et al., An aqueous $\mathrm{Zn}$-ion hybrid supercapacitor with high energy density and ultrastability up to 80000 cycles. Adv. Energy Mater. 9, 1902915 (2019). https://doi.org/10.1002/aenm.201902915

31. H. Wang, M. Wang, Y. Tang, A novel zinc-ion hybrid supercapacitor for long-life and low-cost energy storage applications. Energy Storage Mater. 13, 1-7 (2018). https://doi. org/10.1016/j.ensm.2017.12.022

32. Q. Liu, H. Wang, C. Jiang, Y. Tang, Multi-ion strategies towards emerging rechargeable batteries with high performance. Energy Storage Mater. 23, 566-586 (2019). https:// doi.org/10.1016/j.ensm.2019.03.028

33. L. Dong, W. Yang, W. Yang, Y. Li, W. Wu et al., Multivalent metal ion hybrid capacitors: a review with a focus on zinc-ion hybrid capacitors. J. Mater. Chem. A 7, 13810-13832 (2019). https://doi.org/10.1039/c9ta02678a

34. A. Noori, M.F. El-Kady, M.S. Rahmanifar, R.B. Kaner, M.F. Mousavi, Towards establishing standard performance metrics for batteries, supercapacitors and beyond. Chem. Soc. Rev. 48, 1272-1341 (2019). https://doi.org/10.1039/c8cs00581h

35. M. Song, H. Tan, D. Chao, H. Fan, Recent advances in Zn-ion batteries. Adv. Funct. Mater. 28, 1802564 (2018). https://doi. org/10.1002/adfm.201802564

36. Z. Zhou, X. Zhou, M. Zhang, S. Mu, Q. Liu et al., In situ two-step activation strategy boosting hierarchical porous carbon cathode for an aqueous Zn-based hybrid energy storage device with high capacity and ultra-long cycling life. Small 16, 2003174 (2020). https://doi.org/10.1002/smll.202003174

37. G. Fang, S. Liang, Z. Chen, P. Cui, X. Zheng et al., Simultaneous cationic and anionic redox reactions mechanism enabling high-rate long-life aqueous zinc-ion battery. Adv. Funct. Mater. 29, 1905267 (2019). https://doi.org/10.1002/adfm.201905267

38. E. Frackowiak, F. Béguin, Electrochemical storage of energy in carbon nanotubes and nanostructured carbons. Carbon 40, 1775-1787 (2002). https://doi.org/10.1016/S0008 $-6223(02) 00045-3$

39. X. Jiang, X. Liu, Z. Zeng, L. Xiao, X. Ai et al., A nonflammable $\mathrm{Na}^{+}$-based dual-carbon battery with low-cost, high voltage, and long cycle life. Adv. Energy Mater. 8, 1802176 (2018). https://doi.org/10.1002/aenm.201802176

40. H. Hou, C.E. Banks, M. Jing, Y. Zhang, X. Ji, Carbon quantum dots and their derivative 3D porous carbon frameworks for sodium-ion batteries with ultralong cycle life. Adv. Mater. 27, 7861-7866 (2015). https://doi.org/10.1002/adma.201503816

41. Y. Wang, Z. Wang, Y. Chen, H. Zhang, M. Yousaf et al., Hyperporous sponge interconnected by hierarchical carbon nanotubes as a high-performance potassium-ion battery anode. Adv. Mater. 30, 1802074 (2018). https://doi. org/10.1002/adma.201802074

42. Z. Jian, W. Luo, X. Ji, Carbon electrodes for K-ion batteries. J. Am. Chem. Soc. 137, 11566-11569 (2015). https://doi. org/10.1021/jacs.5b06809 
43. Z. Li, Z. Xu, X. Tan, H. Wang, C.M.B. Holt et al., Mesoporous nitrogen-rich carbons derived from protein for ultra-high capacity battery anodes and supercapacitors. Energy Environ. Sci. 6, 871-878 (2013). https://doi. org/10.1039/C2EE23599D

44. T. Yang, T. Qian, M. Wang, X. Shen, N. Xu et al., A sustainable route from biomass byproduct okara to high content nitrogen-doped carbon sheets for efficient sodium ion batteries. Adv. Mater. 28, 539-545 (2016). https://doi.org/10.1002/ adma.201503221

45. Y. Xie, Y. Chen, L. Liu, P. Tao, M. Fan et al., Ultra-high pyridinic N-doped porous carbon monolith enabling highcapacity K-ion battery anodes for both half-cell and full-cell applications. Adv. Mater. 29, 1702268 (2017). https://doi. org/10.1002/adma.201702268

46. H. Wang, Z. Xu, A. Kohandehghan, Z. Li, K. Cui et al., Interconnected carbon nanosheets derived from hemp for ultrafast supercapacitors with high energy. ACS Nano 7, 5131-5141 (2013). https://doi.org/10.1021/nn400731g

47. S. Chen, L. Ma, K. Zhang, M. Kamruzzaman, C. Zhi et al., A flexible solid-state zinc ion hybrid supercapacitor based on co-polymer derived hollow carbon spheres. J. Mater. Chem. A 7, 7784-7790 (2019). https://doi.org/10.1039/c9ta00733d

48. H. Zhang, Q. Liu, Y. Fang, C. Teng, X. Liu et al., Boosting $\mathrm{Zn}$-ion energy storage capability of hierarchically porous carbon by promoting chemical adsorption. Adv. Mater. 31, 1904948 (2019). https://doi.org/10.1002/adma.201904948

49. P. Yu, Y. Zeng, Y. Zeng, H. Dong, H. Hu et al., Achieving high-energy-density and ultra-stable zinc-ion hybrid supercapacitors by engineering hierarchical porous carbon architecture. Electrochim. Acta 327, 134999 (2019). https://doi. org/10.1016/j.electacta.2019.134999

50. Y. Lu, Z. Li, Z. Bai, H. Mi, C. Ji et al., High energy-power $\mathrm{Zn}$-ion hybrid supercapacitors enabled by layered B/N codoped carbon cathode. Nano Energy 66, 104132 (2019). https ://doi.org/10.1016/j.nanoen.2019.104132

51. P.E. Blöchl, Projector augmented-wave method. Phys. Rev. B 50, 17953-17979 (1994). https://doi.org/10.1103/PhysR evB.50.17953

52. J.P. Perdew, K. Burke, M. Ernzerhof, Generalized gradient approximation made simple. Phys. Rev. Lett. 77, 3865-3868 (1996). https://doi.org/10.1103/PhysRevLett.77.3865

53. B. Hammer, L.B. Hansen, J.K. Nørskov, Improved adsorption energetics within density-functional theory using revised perdew-burke-ernzerhof functionals. Phys. Rev. B 59, 74137421 (1999). https://doi.org/10.1103/PhysRevB.59.7413

54. G. Kresse, D. Joubert, From ultrasoft pseudopotentials to the projector augmented-wave method. Phys. Rev. B 59, 17581775 (1999). https://doi.org/10.1103/PhysRevB.59.1758

55. H.J. Monkhorst, J.D. Pack, Special points for brillouin-zone integrations. Phys. Rev. B 16, 5188-5192 (1976). https://doi. org/10.1103/PhysRevB.13.5188

56. L. Hu, Q. Zhu, Q. Wu, D. Li, Z. An et al., Natural biomass-derived hierarchical porous carbon synthesized by an in situ hard template coupled with $\mathrm{NaOH}$ activation for ultrahigh rate supercapacitors. ACS Sustain. Chem. Eng. 6,
13949-13959 (2018). https://doi.org/10.1021/acssuschem eng.8b02299

57. J. Niu, R. Shao, J. Liang, M. Dou, Z. Li et al., Biomassderived mesopore-dominant porous carbons with large specific surface area and high defect density as high performance electrode materials for Li-ion batteries and supercapacitors. Nano Energy 36, 322-330 (2017). https://doi.org/10.1016/j. nanoen.2017.04.042

58. H. Wang, Q. Gao, J. Hu, High hydrogen storage capacity of porous carbons prepared by using activated carbon. J. Am. Chem. Soc. 131, 7016-7022 (2009). https://doi.org/10.1021/ ja8083225

59. P. Lu, Y. Sun, H. Xiang, X. Liang, Y. Yu, 3D amorphous carbon with controlled porous and disordered structures as a high-rate anode material for sodium-ion batteries. Adv. Energy Mater. 8, 1702434 (2018). https://doi.org/10.1002/ aenm.201702434

60. B. Krüner, A. Schreiber, A. Tolosa, A. Quade, F. Badaczewski et al., Nitrogen-containing novolac-derived carbon beads as electrode material for supercapacitors. Carbon 132, 220-231 (2018). https://doi.org/10.1016/j.carbon.2018.02.029

61. R. Yan, E. Josef, H. Huang, K. Leus, M. Niederberger et al., Understanding the charge storage mechanism to achieve high capacity and fast ion storage in sodium-ion capacitor anodes by using electrospun nitrogen-doped carbon fibers. Adv. Funct. Mater. 29, 1902858 (2019). https://doi.org/10.1002/ adfm.201902858

62. W. Yu, H. Wang, S. Liu, N. Mao, X. Liu et al., N, O-codoped hierarchical porous carbons derived from algae for highcapacity supercapacitors and battery anodes. J. Mater. Chem. A 4, 5973-5983 (2016). https://doi.org/10.1039/c6ta01821a

63. W. Fan, H. Zhang, H. Wang, X. Zhao, S. Sun et al., Dualdoped hierarchical porous carbon derived from biomass for advanced supercapacitors and lithium ion batteries. RSC Adv. 9, 32382-32394 (2019). https://doi.org/10.1039/C9RA0 6914C

64. L. Dong, X. Ma, Y. Li, L. Zhao, W. Liu et al., Extremely safe, high-rate and ultralong-life zinc-ion hybrid supercapacitors. Energy Storage Mater. 13, 96-102 (2018). https://doi. org/10.1016/j.ensm.2018.01.003

65. Z. Guan, H. Liu, B. Xu, X. Hao, Z. Wang et al., Gelatinpyrolyzed mesoporous carbon as a high-performance sodiumstorage material. J. Mater. Chem. A 3, 7849-7854 (2015). https://doi.org/10.1039/C5TA01446H

66. Z. Peng, Y. Hu, J. Wang, S. Liu, C. Li et al., Fullerene-based in situ doping of $\mathrm{N}$ and $\mathrm{Fe}$ into a 3D cross-like hierarchical carbon composite for high-performance supercapacitors. Adv. Energy Mater. 9, 1802928 (2019). https://doi.org/10.1002/ aenm. 201802928

67. D. Xue, D. Zhu, H. Duan, Z. Wang, Y. Lv et al., Deepeutectic-solvent synthesis of N/O self-doped hollow carbon nanorods for efficient energy storage. Chem. Commun. 55, 11219-11222 (2019). https://doi.org/10.1039/C9CC06008A

68. L. Qie, Y. Lin, J.W. Connell, J. Xu, L. Dai, Highly rechargeable lithium- $\mathrm{CO}_{2}$ batteries with a boron- and nitrogen-codoped 
holey-graphene cathode. Angew. Chem. Int. Ed. 56, 69706974 (2017). https://doi.org/10.1002/anie.201701826

69. H. Jia, J. Sun, X. Xie, K. Yin, L. Sun, Cicada slough-derived heteroatom incorporated porous carbon for supercapacitor: ultra-high gravimetric capacitance. Carbon 143, 309-317 (2019). https://doi.org/10.1016/j.carbon.2018.11.011

70. Z. Tian, F. Lai, T. Heil, S. Cao, M. Antonietti, Synthesis of carbon frameworks with $\mathrm{N}, \mathrm{O}$ and S-lined pores from gallic acid and thiourea for superior $\mathrm{CO}_{2}$ adsorption and supercapacitors. Sci. China Mater. 63, 748-757 (2020). https://doi. org/10.1007/s40843-019-1254-9

71. J. Shi, S. Wang, X. Chen, Z. Chen, X. Du et al., An ultrahigh energy density quasi-solid-state zinc ion microbattery with excellent flexibility and thermostability. Adv. Energy Mater. 9, 1901957 (2019). https://doi.org/10.1002/aenm.201901957

72. X. Liu, Y. Yuan, J. Liu, B. Liu, X. Chen et al., Utilizing solar energy to improve the oxygen evolution reaction kinetics in zinc-air battery. Nat. Commun. 10, 4767 (2019). https://doi. org/10.1038/s41467-019-12627-2

73. C. Zhong, B. Liu, J. Ding, X. Liu, Y. Zhong et al., Decoupling electrolytes towards stable and high-energy rechargeable aqueous zinc-manganese dioxide batteries. Nat. Energy 5, 440-449 (2020). https://doi.org/10.1038/s41560-020-0584-y

74. X. Wu, L. Jiang, C. Long, Z. Fan, From flour to honeycomblike carbon foam: carbon makes room for high energy density supercapacitors. Nano Energy 13, 527-536 (2015). https:// doi.org/10.1016/j.nanoen.2015.03.013

75. Y. Wang, R. Liu, Y. Tian, Z. Sun, Z. Huang et al., Heteroatoms-doped hierarchical porous carbon derived from chitin for flexible all-solid-state symmetric supercapacitors. Chem. Eng. J. 384, 123263 (2020). https://doi.org/10.1016/j. cej.2019.123263

76. A. Meng, T. Shen, T. Huang, G. Song, Z. Li et al., $\mathrm{NiCoSe}_{2} /$ $\mathrm{Ni}_{3} \mathrm{Se}_{2}$ lamella arrays grown on $\mathrm{N}$-doped graphene nanotubes with ultrahigh-rate capability and long-term cycling for asymmetric supercapacitor. Sci. China Mater. 63, 229-239 (2020). https://doi.org/10.1007/s40843-019-9587-5

77. Y. Zheng, W. Zhao, D. Jia, Y. Liu, L. Cui et al., Porous carbon prepared via combustion and acid treatment as flexible zincion capacitor electrode material. Chem. Eng. J. 387, 124161 (2020). https://doi.org/10.1016/j.cej.2020.124161

78. L. Dong, W. Yang, W. Yang, C. Wang, Y. Li et al., Highpower and ultralong-life aqueous zinc-ion hybrid capacitors based on pseudocapacitive charge storage. Nano-Micro Lett. 11, 94 (2019). https://doi.org/10.1007/s40820-019-0328-3

79. J. Han, K. Wang, W. Liu, C. Li, X. Sun et al., Rational design of nano-architecture composite hydrogel electrode towards high performance Zn-ion hybrid cell. Nanoscale 10, 1308313091 (2018). https://doi.org/10.1039/C8NR03889A

80. X. Li, X. Xie, R. Lv, B. Na, B. Wang et al., Nanostructured polypyrrole composite aerogels for a rechargeable flexible aqueous $\mathrm{Zn}$-ion battery with high rate capabilities. Energy Technol. 7, 1801092 (2019). https://doi.org/10.1002/ ente. 201801092

81. B. Yang, J. Chen, L. Liu, P. Ma, B. Liu et al., 3D nitrogendoped framework carbon for high-performance potassium ion hybrid capacitor. Energy Storage Mater. 23, 522-529 (2019). https://doi.org/10.1016/j.ensm.2019.04.008

82. J. Ding, H. Zhang, H. Zhou, J. Feng, X. Zheng et al., Sulfur-grafted hollow carbon spheres for potassium-ion battery anodes. Adv. Mater. 31, 1900429 (2019). https://doi. org/10.1002/adma.201900429

83. Y. Liu, H. Dai, L. Wu, W. Zhou, L. He et al., A large scalable and low-cost sulfur/nitrogen dual-doped hard carbon as the negative electrode material for high-performance potassiumion batteries. Adv. Energy Mater. 9, 1901379 (2019). https:// doi.org/10.1002/aenm.201901379

84. J. Chen, B. Yang, H. Hou, H. Li, L. Liu et al., Disordered, large interlayer spacing, and oxygen-rich carbon nanosheets for potassium ion hybrid capacitor. Adv. Energy Mater. 9, 1803894 (2019). https://doi.org/10.1002/aenm.201803894

85. G. Dong, H. Wang, W. Liu, J. Shi, S. Sun et al., Nitrate salt assisted fabrication of highly N-doped carbons for high-performance sodium ion capacitors. ACS Appl. Energy Mater. 1, 5636-5645 (2018). https://doi.org/10.1021/acsaem.8b011 66

86. S.-I. Tobishima, T. Okada, Lithium cycling efficiency and conductivity for high dielectric solvent/low viscosity solvent mixed systems. Electrochim. Acta 30, 1715-1722 (1985). https://doi.org/10.1016/0013-4686(85)87019-5

87. G. Sun, H. Yang, G. Zhang, J. Gao, X. Jin et al., A capacity recoverable zinc-ion micro-supercapacitor. Energy Environ. Sci. 11, 3367-3374 (2018). https://doi.org/10.1039/C8EE0 2567C

88. J. Cui, Z. Guo, J. Yi, X. Liu, K. Wu et al., Organic cathode materials for rechargeable zinc batteries: mechanisms, challenges, and perspectives. Chemsuschem 13, 2160-2185 (2020). https://doi.org/10.1002/cssc.201903265

89. J. Liu, M. Jiao, B. Mei, Y. Tong, Y. Li et al., Carbon-supported divacancy-anchored platinum single-atom electrocatalysts with superhigh Pt utilization for the oxygen reduction reaction. Angew. Chem. Int. Ed. 58, 1163-1167 (2019). https ://doi.org/10.1002/anie.201812423

90. R.G. Amorim, A. Fazzio, A. Antonelli, F.D. Novaes, A.J.R. da Silva, Divacancies in graphene and carbon nanotubes. Nano Lett. 7, 2459-2462 (2007). https://doi.org/10.1021/ $\mathrm{n} 1071217 \mathrm{v}$

91. M. Chen, W. Wang, X. Liang, S. Gong, J. Liu et al., Sulfur/ oxygen codoped porous hard carbon microspheres for highperformance potassium-ion batteries. Adv. Energy Mater. 8, 1800171 (2018). https://doi.org/10.1002/aenm.201800171

92. Y. Sun, H. Xiao, H. Li, Y. He, Y. Zhang et al., Nitrogen/ oxygen co-doped hierarchically porous carbon for high-performance potassium storage. Chem. Eur. J. 25, 7359-7365 (2019). https://doi.org/10.1002/chem.201900448

93. D. Sun, B. Luo, H. Wang, Y. Tang, X. Ji et al., Engineering the trap effect of residual oxygen atoms and defects in hard carbon anode towards high initial coulombic efficiency. Nano Energy 64, 103937 (2019). https://doi.org/10.1016/j.nanoe n.2019.103937

94. D. Yan, Y. Li, J. Huo, R. Chen, L. Dai et al., Defect chemistry of nonprecious-metal electrocatalysts for oxygen reactions. 
Adv. Mater. 29, 1606459 (2017). https://doi.org/10.1002/ adma.201606459

95. D. Datta, J. Li, V.B. Shenoy, Defective graphene as a highcapacity anode material for Na- and Ca-ion batteries. ACS Appl. Mater. Interfaces 6, 1788-1795 (2014). https://doi. org/10.1021/am404788e

96. W. Yang, J. Zhou, S. Wang, W. Zhang, Z. Wang et al., Freestanding film made by necklace-like $\mathrm{N}$-doped hollow carbon with hierarchical pores for high-performance potassium-ion storage. Energy Environ. Sci. 12, 1605-1612 (2019). https:// doi.org/10.1039/C9EE00536F

97. Y. Xu, C. Zhang, M. Zhou, Q. Fu, C. Zhao et al., Highly nitrogen doped carbon nanofibers with superior rate capability and cyclability for potassium ion batteries. Nat. Commun. 9, 1720 (2018). https://doi.org/10.1038/s41467-018-04190-z

98. C. Lv, W. Xu, H. Liu, L. Zhang, S. Chen et al., 3D sulfur and nitrogen codoped carbon nanofiber aerogels with optimized electronic structure and enlarged interlayer spacing boost potassium-ion storage. Small 15, 1900816 (2019). https:// doi.org/10.1002/smll.201900816

99. X. Fan, J. Liu, Z. Song, X. Han, Y. Deng et al., Porous nanocomposite gel polymer electrolyte with high ionic conductivity and superior electrolyte retention capability for long-cycle-life flexible zinc-air batteries. Nano Energy 56, 454-462 (2019). https://doi.org/10.1016/j.nanoe n.2018.11.057

100. Y. Li, X. Fan, X. Liu, S. Qu, J. Liu et al., Long-battery-life flexible zinc-air battery with near-neutral polymer electrolyte and nanoporous integrated air electrode. J. Mater. Chem. A 7, 25449-25457 (2019). https://doi.org/10.1039/C9TA09137H

101. Y. Zhu, X. Yang, T. Liu, X. Zhang, Flexible 1D batteries: recent progress and prospects. Adv. Mater. 32, 1901961 (2020). https://doi.org/10.1002/adma.201901961 